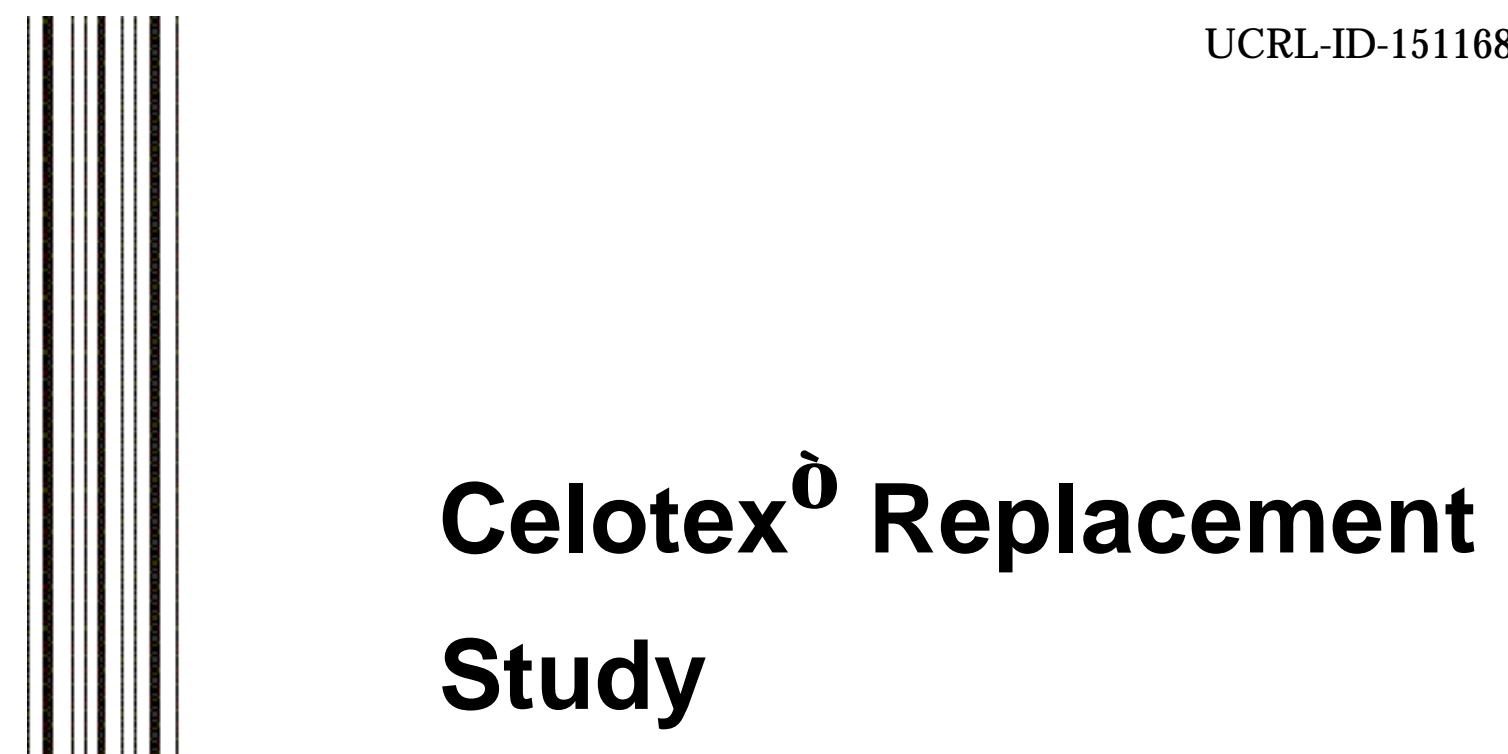

S. Couture, R. Hafner

\title{
October 1, 2002
}

U.S. Dopartment of Energy

Low

Livermore

National

Laboratory

Approved for public release; further dissemination unlimited 


\section{DISCLAIMER}

This document was prepared as an account of work sponsored by an agency of the United States Government. Neither the United States Government nor the University of California nor any of their employees, makes any warranty, express or implied, or assumes any legal liability or responsibility for the accuracy, completeness, or usefulness of any information, apparatus, product, or process disclosed, or represents that its use would not infringe privately owned rights. Reference herein to any specific commercial product, process, or service by trade name, trademark, manufacturer, or otherwise, does not necessarily constitute or imply its endorsement, recommendation, or favoring by the United States Government or the University of California. The views and opinions of authors expressed herein do not necessarily state or reflect those of the United States Government or the University of California, and shall not be used for advertising or product endorsement purposes.

This work was performed under the auspices of the U. S. Department of Energy by the University of California, Lawrence Livermore National Laboratory under Contract No. W-7405-Eng-48.

This report has been reproduced directly from the best available copy.

Available electronically at http://www.doc.gov/bridge

Available for a processing fee to U.S. Department of Energy

And its contractors in paper from

U.S. Department of Energy

Office of Scientific and Technical Information

P.O. Box 62

Oak Ridge, TN 37831-0062

Telephone: (865) 576-8401

Facsimile: (865) 576-5728

E-mail: reports@adonis.osti.gov

Available for the sale to the public from

U.S. Department of Commerce

National Technical Information Service

5285 Port Royal Road

Springfield, VA 22161

Telephone: (800) 553-6847

Facsimile: (703) 605-6900

E-mail: orders@ntis.fedworld.gov

Online ordering: http://www.ntis.gov/ordering.htm

OR

Lawrence Livermore National Laboratory

Technical Information Department's Digital Library

http://www.llnl.gov/tid/Library.html 


\section{Acknowledgements}

The authors would like to acknowledge the LLNL staff who contributed to this study and the completion of the report. In particular we would like to thank:

- Peter Raboin who performed the 3-D structural analysis of the AL-R8 SI 4 Pack 20-ft drops,

- Bob Woelffer who designed and coordinated the drop tests at Site 300,

- Adriano Salamanca and John Rountree who performed the container leak tests,

- Sherif Abdallah who oversaw the original work and prepared the Preliminary Draft, and

- Lyssa Campbell for technical editing and support.

In addition, thanks go to Blair Rhodes, Jeff Addington and their associates at Pantex who supplied parts and materials LLNL used to develop their test configurations and who developed and supplied the test and qualification methods for the AL-R8 SI. 


\section{Acronyms}

\begin{tabular}{|l|l|}
\hline CHN & carbon, hydrogen, nitrogen \\
\hline DOE & U.S. Department of Energy \\
\hline DOE/AL & DOE Albuquerque \\
\hline HAC & hypothetical accident conditions \\
\hline LANL & Los Alamos National Laboratory \\
\hline LLNL & Lawrence Livermore National Laboratory \\
\hline MCNP & $\begin{array}{l}\text { A three-dimensional Monte Carlo radiation } \\
\text { transport code }\end{array}$ \\
\hline NCT & normal conditions of transport \\
\hline RTD & resistive temperature device \\
\hline SI & Sealed Insert \\
\hline SNL & Sandia National Laboratory \\
\hline
\end{tabular}




\section{Executive Summary}

The AL-R8 is the pit storage container in most widespread use at Pantex. The AL-R8 container family consists of standard 20-in.-diameter steel drums, 30 to $60 \mathrm{in}$. in height, with insulation inserts made of Celote $x^{\circledR}$ - a fiberboard product made from processed sugar cane. Celotex is an acceptable material for inserts in many radioactive material shipping and storage containers. It is a good shock mitigator/insulator, does a fair job in fire protection (when oxygen is excluded), shielding, and criticality, and is inexpensive and easily available. However, the fiberboard absorbs water in humid environments which, when combined with chemical residues in the fiberboard, forms corrosive compounds that can shorten the life of the container and affect container contents. To protect the contents from this potentially damaging environment, the AL-R8 SI was developed to isolate the contents within a sealed stainless steel vessel inside the AL-R8. Although the SI protected the contents, corrosion studies indicated the SI lid bolts might corrode over time and surveillance showed that areas of the outer drum were still subject to corrosion. To address this potential problem, DOE/Albuquerque sponsored bolt and Celotex replacement studies. The bolt replacement study was assigned to Mason and Hanger's Pantex Facility and this Celotex Replacement Study to Lawrence Livermore National Laboratory.

The Celotex Replacement Study evaluated options for replacing Celotex with a material that is chemically compatible with the AL-R8 SI container. The evaluation was limited to materials either used previously in nuclear materials shipping and storage containers or materials with known properties in a low-radiation environment. This limitation was set to ensure that the long-term aging effect on the new material is known a priori. Initial material evaluations narrowed the material choices to foam and cork. Although cork performed better than foam in some tests, cork was considered a less advantageous replacement material due to the potential need for additional poisons to avoid criticality concerns for unlimited arrays, potential varia bility in its performance due to expected variations in natural materials, potential availability concerns for long term use, and increased container weight and cost. For these reasons, an all-foam replacement design was selected for direct comparison to Celotexusing the AL-R8 SI test requirements. The materials were compared in drop tests, thermal equilibrium tests, fire tests, and vibration tests. In addition, analyses of the materials were compared for chemical compatibility and structural, thermal, shielding, and criticality performance.

The study found the General Plastics FR-3700 Last-A-Foam ${ }^{\circledast}$ family of polyurethane foams to be a good alternative to Celotex and a superior choice for applications where there are material compatibility concerns and fire resistance, thermal and structural performance requirements. The design shown in Figure 5.1.a is an example where a combination of GP FR-3700 series Last-A-Foam materials were used to design a package meeting such requirements. Test and analysis have shown that this design met or exceeded the performance requirements of the AL-R8 SI using Celotex. Based on the tests and analysis conducted to date, the FR-3700 family of foams should be a good candidate to replace Celotex in AL-R8 SI containers. The current estimated cost of the material ( $\$ 300 /$ container) could be further reduced by working with the vendor to set up the manufacturing and molding process. 
This page is intentionally blank. 


\section{Contents}

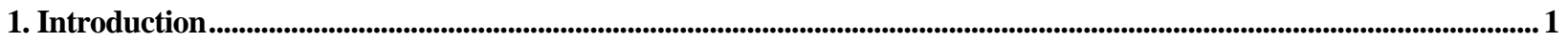

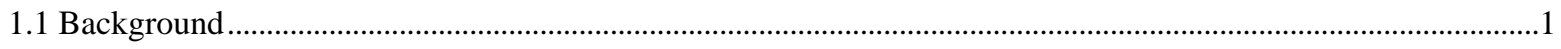

1.2 Scope

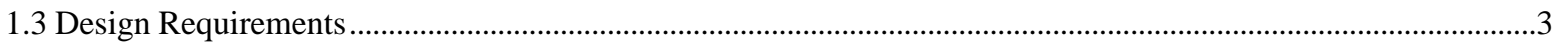

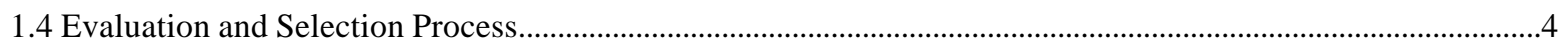

2. Material Properties and Chemical Analysis.................................................................................................................................5

2.1 Material Properties of GP FR-3700 Foams ……………...............................................................................

2.2 Thermal Properties of GP FR-3700 foams ………………............................................................................

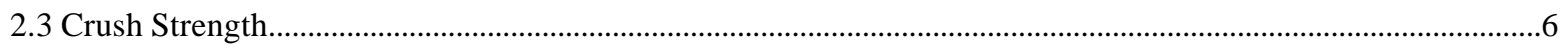

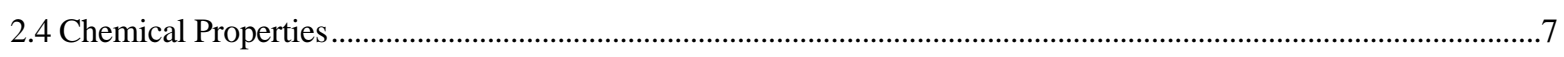

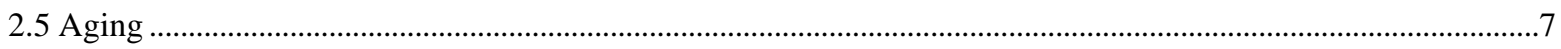

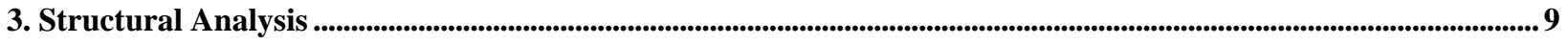

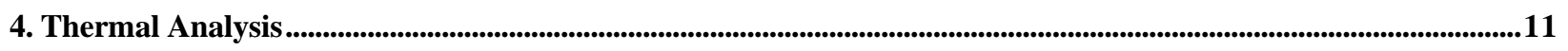

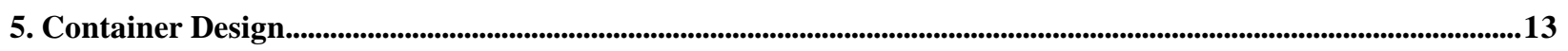

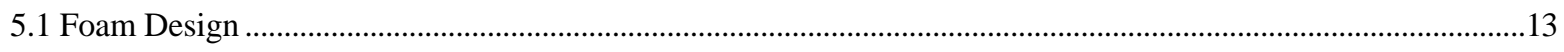

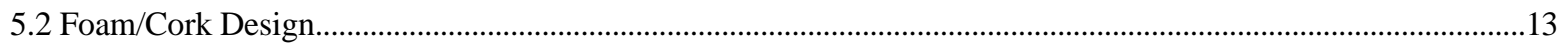

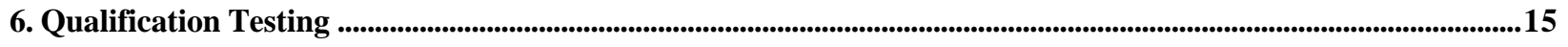

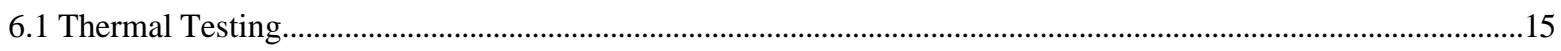

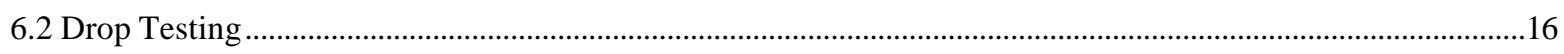

6.2.1 20-ft Drop Test............................................................................................................................

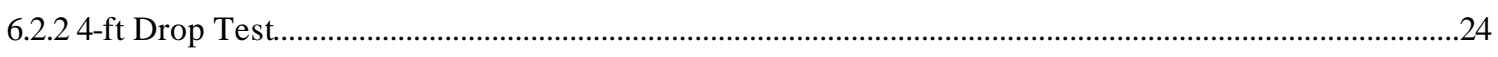

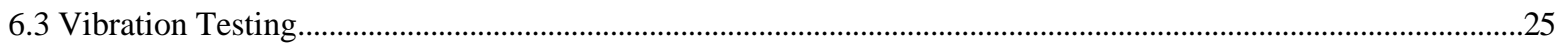

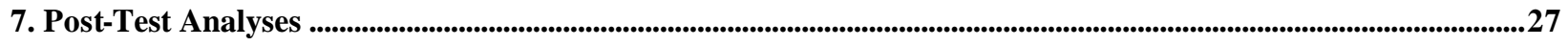

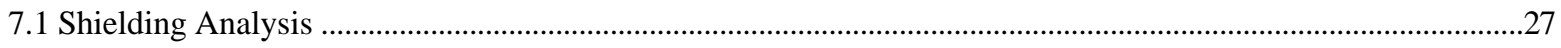

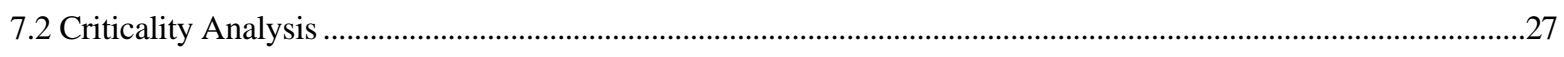

7.3 Fire Protection

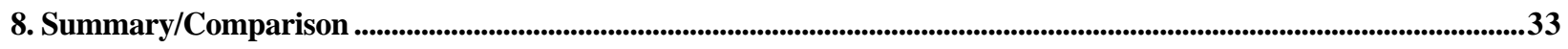

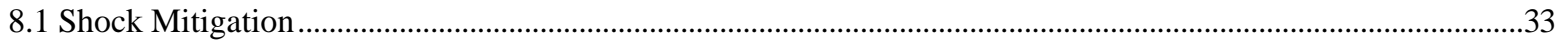

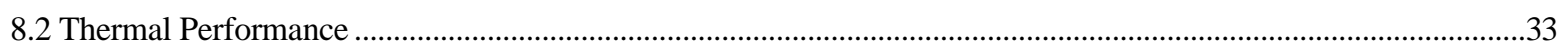

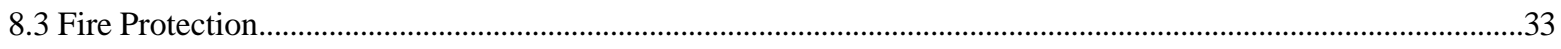

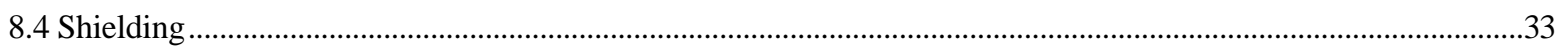

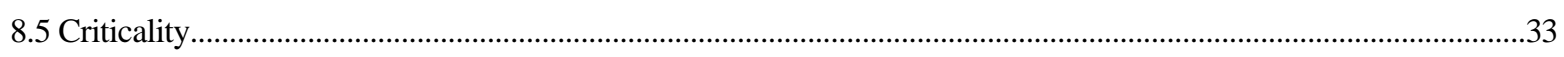

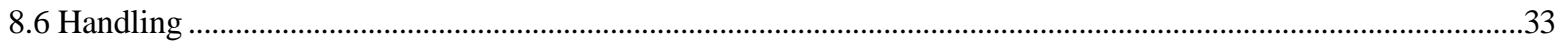

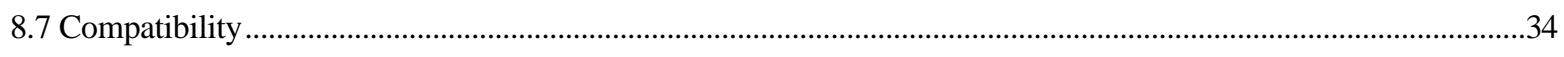

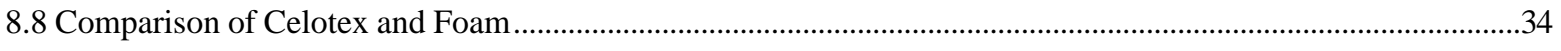

9. Conclusions and Recommendations .....................................................................................................................................................35

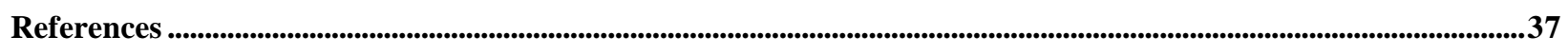

Appendix A. Selected Engineering Drawings …………............................................................................................................................ A-1 


\section{Figures}

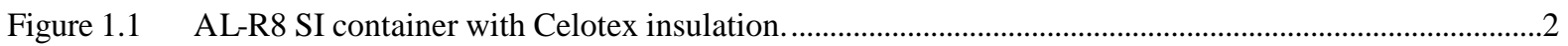

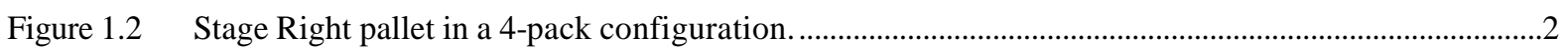

Figure 3.1.a Cross-section of a Stage Right 4-pack...........................................................................................

Figure 3.1.b Foam/cork container cross-section (with SI vessels removed for clarity).............................................

Figure 3.2.a Code prediction of post-drop condition for a foam/cork 4-pack 20-ft drop..........................................10

Figure 3.2.b AL-R8 SI foam/cork 4-pack after a 20-ft drop.......................................................................................10

Figure 4.1 Drawing of AL-R8 SI showing locations of the RTDs for thermal modeling and testing...................11

Figure 4.2 Model predictions for temperatures at RTD locations 2, 6, 10, and 15 for a container with

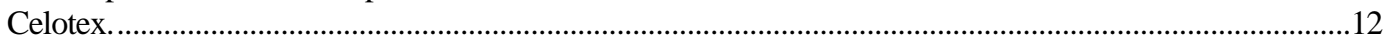

Figure 5.1.a AL-R8 SI with foam inserts.................................................................................................................14

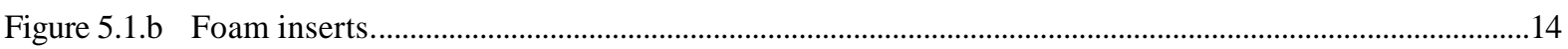

Figure 5.2 AL-R8 SI with foam/cork inserts................................................................................................

Figure 6.1 Pit temperature above ambient for Celotex, foam, and foam/cork materials.........................................16

Figure 6.2 Preparing for the 20-ft drop test at the 100-ft drop tower at LLNL Site 300..........................................17

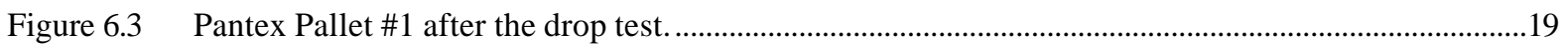

Figure 6.4 Pantex Pallet \#2 ready for the drop test...........................................................................................19

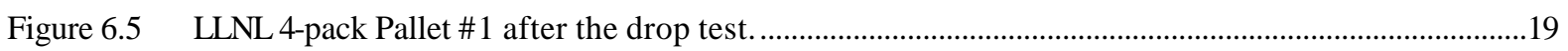

Figure 6.6 Accelerometer locations on the SI flange (top shown) for the foam container...................................19

Figure 6.7 High-speed camera field of view for drop tests 1 and 2 (A) and test 3 (B)........................................20

Figure 6.8 High-speed camera frames showing: (a) pallet first contact with the target plate, (b) pallet deflection due to impact, (c) end of downward motion, and (d) first rebound...................................20

Figure 6.9 Data from high-speed camera frame analysis for the Pallet \#1 drop test..............................................21

Figure 6.10 Container after the 20-ft drop test (steel drum deformed from impact). ..................................................22

Figure 6.11 Stainless steel fixture after the 20-ft drop. (Notice the bent lower plate.)...........................................22

Figure 6.12 Unfiltered accelerometer data from drop tests with foam and foam/cork insulation.............................23

Figure 6.13 Filtered accelerometer data. ............................................................................................................24

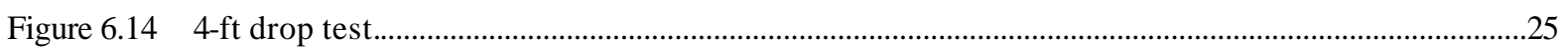

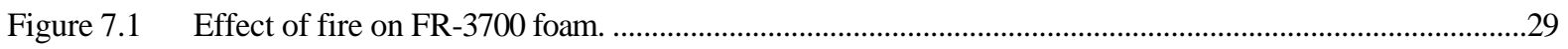

Figure 7.2 Test setup for the foam fire test conducted by General Plastic...........................................................30

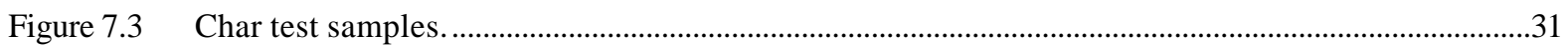

Figure A-1 Drawing Number AAA00-113768-00, AL-R8 SI Thermal Test Assembly ........................................A-2

Figure A-2 Drawing Number AAA99-101480-00, End Foam...............................................................................

Figure A-3 Drawing Number AAA99-101481-00, Mid Foam..............................................................................

Figure A-4 Drawing Number AAA99-101483-00, Ring Foam...........................................................................

Figure A-5 Drawing Number AAA99-101484-00, Flange Foam ........................................................................... 


\section{Tables}

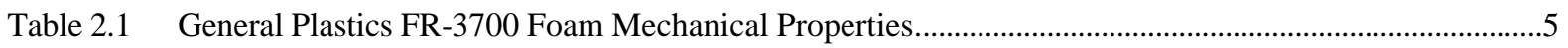

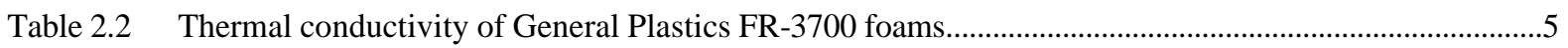

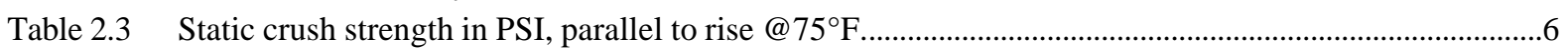

Table 2.4 Static crush strength in PSI, perpendicular to rise @ $75^{\circ} \mathrm{F}$.....................................................................6

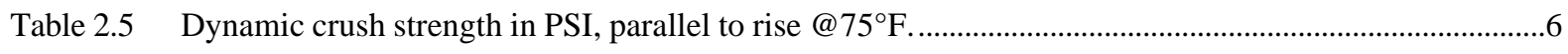

Table 2.6 Dynamic crush strength in PSI, perpendicular to rise @ $75^{\circ} \mathrm{F}$.............................................................6

Table 2.7 Effect of temperature on foam compressive strength (PSI) . ..............................................................

Table 2.8 General Plastics FR-3700 chemical analysis for corrosive agents..........................................................

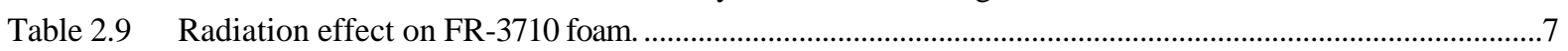

Table 6.1 Accelerometer data (average) for the 20 -ft drop test.....................................................................23

Table 6.2 Summary of vertical vibration from the 3 -axis accelerometer...............................................................26

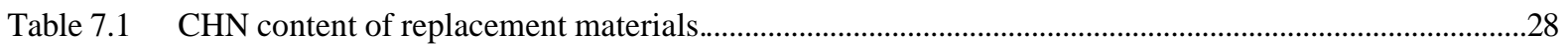

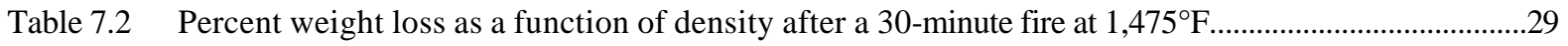

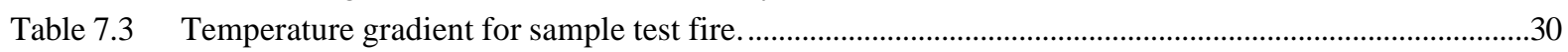

Table 8.1 Comparative performance of Celotex and the GP FR-3700 foam. ..........................................................34 
This page is intentionally blank. 


\section{Introduction}

\subsection{Background}

The AL-R8 is the pit storage container in most widespread use at Pantex. The AL-R8 container family consists of standard 20-in. diameter steel drums, 30 to 60 inches in height, with insulation inserts made of fiberboard. The fiberboard is made into disks that support the pit fixture in the middle of the container, providing impact and thermal protection for the pit. The fiberboard material-known and herein called by the trade name Celote $x^{\circledR}$ - is made from sugar cane fibers (cellulose) bonded together with organic glue. Since it is a by-product of the sugar industry, it is relatively inexpensive and readily available. Because of its good insulation and shock mitigation properties and low cost, Celotex is widely used to transport radioactive materials. However, as an insulating material for long-term storage containers, Celotex has a number of drawbacks.

Celotex can absorb large amounts of water in humid environments. Variations in the moisture content of Celotex, as well as natural variations in the material itself, lead to undesirable variations in its thermal properties, fire resistance, shielding, and moderating properties. In addition, this absorbed water combines with chemical residues in the Celotex to form corrosive compounds that can shorten the life of the container and affect container contents. During container surveillance, interior surfaces of untreated mild steel AL-R8 drums were observed completely covered with rust scale in only a few years. For drums with protective coatings, Celotex has led to corrosion in as little as two years at spots where the coating was damaged, especially on drum lids, drum lips, and clamp rings. To protect the contents from this potentially damaging environment, the AL-R8 SI was developed to isolate the contents within a sealed stainless steel vessel inside the AL-R8.

Figure 1.1 shows the current AL-R8 SI container with Celotex as the insulation/shock mitigation material. The container consists of an outer steel drum with a 20-in. diameter and 30-in. length (derived from the original AL-R8 2030). Celotex disks fill the space between the outer steel drum and the inner stainless steel vessel. The sealed insert (SI) contains the pit, which is mounted in a stainless steel or carbon steel fixture commonly referred to as a "birdcage." Figure 1.2 shows the storage configuration for the AL-R8 and the new AL-R8 SI containers in what is known as the 4pack Stage Right pallet. The pallets are configured in "4-pack" and "6-pack" arrangements that can be stacked together in any combination.

Since Celotex is still used as the thermal/shock mitigation material in the AL-R8 SI container, concerns have been raised regarding possible corrosion of the carbon steel bolts holding the SI lid to its body. To understand this potential problem, DOE/Albuquerque (DOE/AL) sponsored bolt and Celotex replacement studies. The bolt replacement study was assigned to Mason and Hanger's Pantex Facility and the Celotex replacement study to Lawrence Livermore National Laboratory (LLNL). 


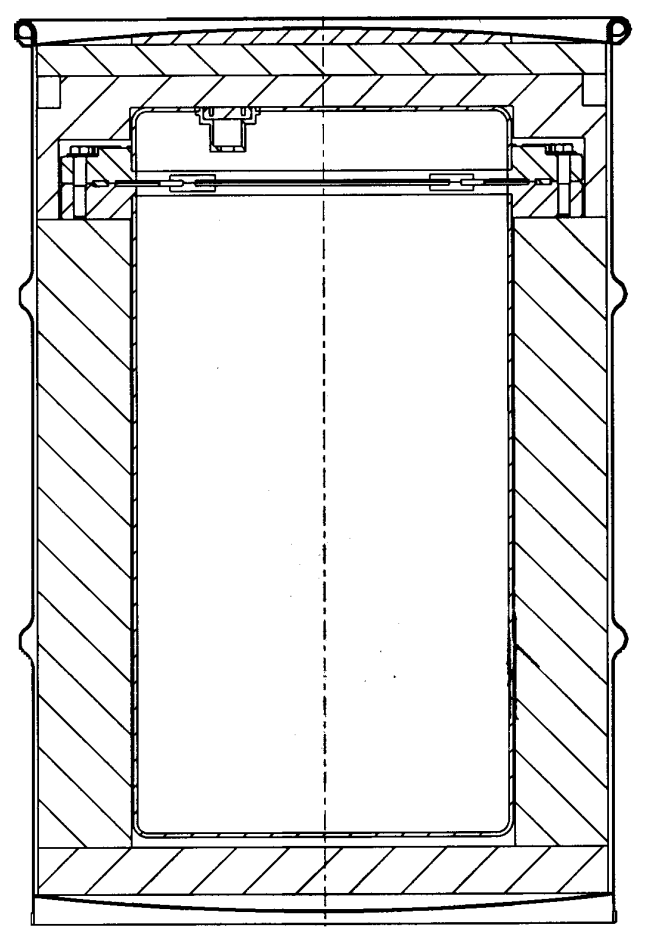

Figure 1.1 AL-R8 SI container with Celotex insulation.

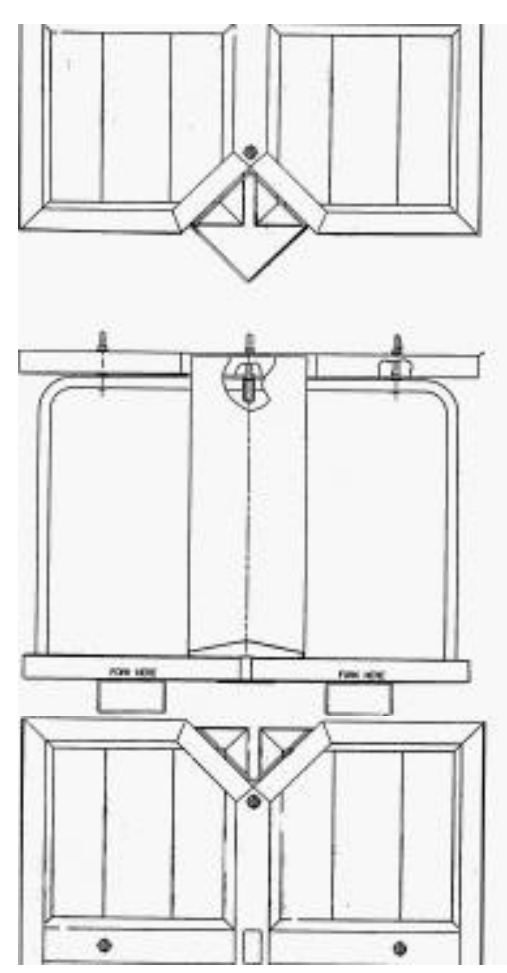

Figure 1.2 Stage Right pallet in a 4-pack configuration.

\subsection{Scope}

The scope of the Celotex Replacement Study is to evaluate options for replacing Celotex with a new material that is chemically compatible with the AL-R8 SI container. The evaluation was limited to materials either used previously in nuclear materials shipping and storage containers or materials with known properties in a low-radiation environment. This limitation was set to ensure that the long-term aging effect on the new material is known a priori. Descriptions of the materials evaluated in this study follow.

1. Polyurethane Foam - General Plastics Last-A-Foam ${ }^{\circledR}$ FR-3700. This is a family of polyurethane closed-cell foams specifically formulated for nuclear materials containers. This is the same family of foams used in AT-400 containers and other containers designed by Sandia National Laboratory (SNL).

2. Cork material - Global Technology System P-45 and P-27 cork. This is the same type of material used in the Los Alamos National Laboratory (LANL) SAFKEG 2863B container (LANL 1997a). This material was chosen because of its excellent shock mitigation properties and superior fire resistance.

3. Vapor barrier coatings - Silicon-based coating from Dow Corning, 749 Vapor-Block from Vimasco Corporation, water-based catalyzed epoxy from Sherwin-Williams, and shrink-wrap polyethylene and polypropylene copolymer plastic films.

The vapor barrier coatings proved to be the biggest challenge as the material needed to be durable enough to seal the Celotex but light enough to maintain the Celotex shock and thermal properties. The shrink-wrap 
material, which initially looked promising, was not selected due to potential Celotex exposure if the barrier failed, as well as the increased cost and weight of the final package.

The two candidates selected for further evaluation were the General Plastics FR-3700 foams and the cork material. Based on direction from DOE/AL, the evaluation of the new material was expanded during the testing phase from a comparative analysis to full qualification testing. The testing followed Pantex AL-R8 SI qualification testing procedures (Addington 2000a and 2000b).

This document describes the analysis, design concept, and the test results of this evaluation.

\subsection{Design Requirements}

The new material should meet AL-R8 SI design requirements in the following areas as described in the AL-R8 Qualification Plan (Addington 2000b).

- Thermal - The container shall meet or exceed the performance of the AL-R8 container by producing equilibrium pit surface temperatures that are equal to or lower than the AL-R8 at the same ambient storage temperatures. This is to be demonstrated for pit types " $A$ " through " $E$ " and the remaining " $\mathrm{C}$ " type as described in the LLNL thermal study letter on the AL-R8 configuration (LLNL 1998).

- $\quad$ Drop test - The container shall meet the $1 \times 10^{-7} \mathrm{cc} / \mathrm{s}$ (air) $)_{\text {st }}$ AL-R8 SI leak-check criteria following a 4-ft bare container drop test and a 20-ft drop test in the 4-pack Stage Right pallet configuration.

- Fire protection - The container shall survive a 30 -minute fuel fire at $1,475^{\circ} \mathrm{F}$ with no increase in external radioactive source term as demonstrated by no pressure rupture of the container. This is to be demonstrated through engineering analysis by calculating the resulting pressure increase in the container and verified by empirical data at the flange/bolt interface.

- Vibration damping - The container shall meet or exceed the performance of the Model FL configuration for normal transportation as indicated by comparison of the vibration level experienced by simulated pit contents.

Additionally, the container shall meet shielding and criticality safety requirements and be chemically compatible with all exposed container materials. The container weight should be no greater than the existing AL-R8 SI. The material should be easily and safely handled and assembled and the cost of manufacturing and delivering replacement material should not exceed $\$ 300.00$ per container. 


\subsection{Evaluation and Selection Process}

The evaluation and selection process involved analysis of candidate materials, design and analysis of containers using replacement materials, and testing of the proposed designs. A description of each section in this document follows.

1. Section 2. Materials research and analysis to support the design effort and screen for corrosive constituents.

2. Section 3. Structural analysis of the 4-pack container configuration to develop an understanding of the interaction between different package and pallet design elements on package performance during 20-ft drops. The 4-pack configuration was analyzed since it is the most common drop-test configuration.

3. Section 4. A thermal analysis of the single container configuration was conducted since most of the previous thermal testing was conducted using the single container configuration. This analysis was used for comparative evaluation of the different candidate replacement materials.

4. Section 5. Thermal and structural analyses were used to develop container designs using replacement materials that were predicted to meet or exceed the AL-R8 SI design requirements.

5. Section 6. The Celotex in test AL-R8 SI containers was replaced with candidate materials per designs described in Section 5. The containers were evaluated for structural and thermal performance against the original AL-R8 SI design.

6. Section 7. Shielding, criticality, and fire analyses were completed on the most successful candidate materials.

7. Section 8. Results of the analysis and testing were evaluated against design criteria (and options were comparatively evaluated) to determine whether (a) candidate replacement materials met requirements and (b) a particular option was preferable to the others.

8. Section 9. The conclusions and recommendations from the study. 


\section{Material Properties and Chemical Analysis}

A material analysis was performed for each candidate material to determine the:

- material weight and density for use in shielding and criticality analyses,

- moisture content and decomposition temperature for use in corrosion, thermal, fire, and criticality analyses, and

- carbon, hydrogen, and nitrogen $(\mathrm{CHN})$ content for use in criticality analyses.

Material analysis data for candidate materials are presented later in appropriate sections of this report. Table 2.1, below, lists properties of the foams, the principle candidate materials described in this report.

\subsection{Material Properties of GP FR-3700 Foams}

The two foams selected for testing, FR-3715 and FR-3730, are similar in their chemical composition and vary only in their weight densities, which are $15-\mathrm{lb} / \mathrm{ft}^{3}$ and $30-\mathrm{lb} / \mathrm{ft}^{3}$, respectively. Table 2.1 presents mechanical properties of these two foams and their thermal properties are summarized in Section 2.2 (General Plastics 2002).

Table 2.1 General Plastics FR-3700 Foam Mechanical Properties.

\begin{tabular}{|c|c|c|c|c|c|c|c|c|}
\hline \multirow{2}{*}{ Foam } & \multicolumn{2}{|c|}{$\begin{array}{r}\text { Tensile Strength, } \\
\text { PSI }\end{array}$} & \multicolumn{2}{|c|}{$\begin{array}{c}\text { Compressive } \\
\text { Strength, PSI }\end{array}$} & Shear Strength, PSI & \multicolumn{2}{c|}{$\begin{array}{c}\text { Modulus of Elasticity, } \\
\text { PSI }\end{array}$} \\
\hline & $\begin{array}{c}\text { Parallel } \\
\text { to } \\
\text { surface }\end{array}$ & $\begin{array}{c}\text { Normal } \\
\text { to } \\
\text { surface }\end{array}$ & $\begin{array}{c}\text { Parallel } \\
\text { to } \\
\text { surface }\end{array}$ & $\begin{array}{c}\text { Normal } \\
\text { to } \\
\text { surface }\end{array}$ & $\begin{array}{c}\text { Parallel to } \\
\text { surface }\end{array}$ & $\begin{array}{c}\text { Normal } \\
\text { to } \\
\text { surface }\end{array}$ & $\begin{array}{c}\text { Parallel to } \\
\text { surface }\end{array}$ & $\begin{array}{c}\text { Normal to } \\
\text { surface }\end{array}$ \\
\hline FR-3715 & 418.0 & 358.0 & 360.7 & 286.0 & 264.0 & 275.0 & 9,606 & 7,457 \\
\hline FR-3730 & 1,481 & 1,639 & 2,128 & 2,352 & 1,439 & 1,247 & 52,229 & 67,079 \\
\hline
\end{tabular}

\subsection{Thermal Properties of GP FR-3700 foams}

The coefficient of linear thermal expansion is $3.4 \times 10^{-5} \mathrm{in} . / \mathrm{in} . /^{\circ} \mathrm{F}$ from $-50^{\circ} \mathrm{F}$ to $200^{\circ} \mathrm{F}$ for both GP FR-3715 and FR-3730.

Table 2.2 Thermal conductivity of General Plastics FR-3700 foams.

\begin{tabular}{|c|c|}
\hline Thermal Conductivity & (W/m·K) \\
\hline FR-3715 & 0.0317 \\
\hline FR-3730 & 0.0682 \\
\hline
\end{tabular}




\subsection{Crush Strength}

The crush properties for the GP FR-3700 polyurethane foam are shown in Tables 2.3 through 2.6 as published by the General Plastics Manufacturing Company (General Pla stics 2002). Tables 2.3 and 2.4 list the static strengths as a function of strain at room temperature while Tables 2.5 and 2.6 list the dynamic strength at various strains at room temperature. Table 2.7 lists the effect of temperature on the tensile and compressive strength of the foams.

Table 2.3 Static crush strength in PSI, parallel to rise @ $75^{\circ} \mathrm{F}$.

\begin{tabular}{|c|c|c|c|c|c|}
\hline $\begin{array}{c}\text { Strain/ } \\
\text { Density lbs/ft }\end{array}$ & $\mathbf{1 0 \%}$ & $\mathbf{2 0 \%}$ & $\mathbf{3 0 \%}$ & $\mathbf{4 0 \%}$ & $\mathbf{5 0 \%}$ \\
\hline GP FR-3715 & 732 & 737 & 792 & 900 & 1,103 \\
\hline GP FR-3730 & 2,117 & 2,394 & 2,647 & 3,130 & 4,127 \\
\hline
\end{tabular}

Table 2.4 Static crush strength in PSI, perpendicular to rise @ $75^{\circ} \mathbf{F}$.

\begin{tabular}{|c|c|c|c|c|c|}
\hline $\begin{array}{c}\text { Strain/ } \\
\text { Density lbs/ft }\end{array}$ & $\mathbf{1 0 \%}$ & $\mathbf{2 0 \%}$ & $\mathbf{3 0 \%}$ & $\mathbf{4 0 \%}$ & $\mathbf{5 0 \%}$ \\
\hline GP FR-3715 & 698 & 726 & 779 & 873 & 1,081 \\
\hline GPFR-3730 & 2,507 & 2,749 & 2,984 & 3,390 & 4,426 \\
\hline
\end{tabular}

Table 2.5 Dynamic crush strength in PSI, parallel to rise @ $75^{\circ} \mathrm{F}$.

\begin{tabular}{|c|c|c|c|c|c|}
\hline $\begin{array}{c}\text { Strain/ } \\
\text { Density lbs/ft }\end{array}$ & $\mathbf{1 0 \%}$ & $\mathbf{2 0 \%}$ & $\mathbf{3 0 \%}$ & $\mathbf{4 0 \%}$ & $\mathbf{5 0 \%}$ \\
\hline GP FR-3715 & 691 & 710 & 766 & 864 & 1,064 \\
\hline GP FR-3730 & 2,324 & 2,765 & 3,156 & 3,870 & 5,426 \\
\hline
\end{tabular}

Table 2.6 Dynamic crush strength in PSI, perpendicular to rise @ $75^{\circ} \mathrm{F}$.

\begin{tabular}{|c|c|c|c|c|c|}
\hline $\begin{array}{c}\text { Strain/ } \\
\text { Density lbs/ft }\end{array}$ & $\mathbf{1 0 \%}$ & $\mathbf{2 0 \%}$ & $\mathbf{3 0 \%}$ & $\mathbf{4 0 \%}$ & $\mathbf{5 0 \%}$ \\
\hline GP FR-3715 & 673 & 706 & 759 & 857 & 1,061 \\
\hline GP FR-3730 & 2,390 & 2,632 & 2,903 & 3,420 & 4,476 \\
\hline
\end{tabular}


Table 2.7 Effect of temperature on foam compressive strength (PSI).

\begin{tabular}{|c|c|c|c|c|}
\hline Foam & \multicolumn{2}{|c|}{ Parallel to rise } & \multicolumn{2}{c|}{ Perpendicular to rise } \\
\hline & $\mathbf{7 5}^{\circ} \mathbf{F}$ & $\mathbf{2 5 0}^{\mathbf{}} \mathbf{F}$ & $\mathbf{7 5}^{\circ} \mathbf{F}$ & $\mathbf{2 5 0}^{\mathbf{}} \mathbf{F}$ \\
\hline GP FR-3715 & 723 & 295 & 753 & 311 \\
\hline GP FR-3730 & 2,540 & 1,028 & 2,708 & 1,025 \\
\hline
\end{tabular}

\subsection{Chemical Properties}

Table 2.8 lists the concentration of potentially corrosive compounds in the FR-3700 family of polyurethane foams (Heinrichs 2000). The total concentration is slightly less than $10 \mathrm{mg} / \mathrm{kg}$

(or $<10 \mathrm{ppm}$ ).

Table 2.8 General Plastics FR-3700 chemical analysis for corrosive agents.

\begin{tabular}{|l|l|}
\hline Material & Weight \\
\hline Chloride & $6.7 \mathrm{mg} / \mathrm{kg}$ \\
\hline Sulfate & $1.5 \mathrm{mg} / \mathrm{kg}$ \\
\hline Nitrate & $1.7 \mathrm{mg} / \mathrm{kg}$ \\
\hline
\end{tabular}

\subsection{Aging}

Regarding aging data and long-term effect of radiation on the urethane foam, Table 2.9 shows the performance of the FR-3710 foam when exposed to different levels of radiation dose. As indicated by the data, there is no degradation of the compressive properties of the foam even when exposed to a much higher dose than expected during its service life (Edmondson 1994).

Table 2.9 Radiation effect on FR-3710 foam.

\begin{tabular}{|l||c|c|c|c|c|c|c|c|c|}
\cline { 2 - 11 } \multicolumn{1}{||}{} & Density & \multicolumn{7}{|c|}{ Compressive Stress (PSI) } \\
\hline Treatment & $\mathbf{l b s / f ^ { \mathbf { 3 } }}$ & $\mathbf{1 0 \%}$ & $\mathbf{2 0 \%}$ & $\mathbf{3 0 \%}$ & $\mathbf{4 0 \%}$ & $\mathbf{5 0 \%}$ & $\mathbf{6 0 \%}$ & $\mathbf{6 5 \%}$ & $\mathbf{7 0 \%}$ \\
\hline Control & 10.78 & 352 & 359 & 382 & 426 & 508 & 686 & 851 & 1,121 \\
\hline $\mathbf{2} \times \mathbf{1 0}^{\mathbf{7}}$ Rads & 10.68 & 341 & 348 & 373 & 417 & 499 & 678 & 848 & 1,137 \\
\hline $\mathbf{4 . 2} \times \mathbf{1 0}^{\mathbf{7}}$ Rads & 10.58 & 328 & 336 & 360 & 405 & 488 & 666 & 835 & 1,122 \\
\hline $\mathbf{7} \times \mathbf{1 0}^{\mathbf{7}}$ Rads & 10.64 & 333 & 341 & 366 & 408 & 491 & 666 & 831 & 1,106 \\
\hline $\mathbf{2} \times \mathbf{1 0}^{\mathbf{8}}$ Rads & 10.76 & 347 & 356 & 380 & 422 & 507 & 682 & 844 & 1,112 \\
\hline
\end{tabular}


This page is intentionally blank. 


\section{Structural Analysis}

To evaluate the performance of the various candidate materials in a 4-pack storage configuration and predict the loads on the container content during a 20 -ft drop, detailed finite element models of the 4-pack Stage Right pallet were created by Peter Raboin (2000) of LLNL. With the exception of the pitch impact analysis, which used a 180-degree symmetry model, a detailed 3D model of the entire 4-pack pallet was used for all structural analyses. The finite element models were based on known parameters and were used to study structural performance of the AL-R8 SI when dropped in different packing configurations, at various 3D impact angles (pitch and roll), using different candidate materials, and assorted combinations thereof. DYNA3D (LLNL 1999) simulations were used to predict the impact response $g$-loading on the contents of AL-R8 SIs during these simulated 20-ft drop tests. Cross-sections of the finite element model of the foam/cork design are shown in Figures 3.1.a and 3.1.b.

The calculations showed that, as expected, the packing material had an appreciable effect on the $g$-loads experienced inside the SI and that the $g$-loads varied between containers depending upon their position in the 4-pack. The 4-pack frame's bolt design (the bolts hold the pallet top cover to the pallet) allowed the structure to be properly pre-stressed. The DYNA3D code showed that the lateral bolts that hold the 4-pack together had a significant impact on the expected damage to the AL-R8 SI containers, especially the lid. The code also showed that, depending on pre-load, the lateral bolts may fail. In one of the drop tests, the bolts failed in the manner the code predicted. Figure 3.2.a shows the predicted deformation for the 4-pack pallets from a 20-ft drop. Figure 3.2.b shows a picture of the 4-pack after the actual drop test. Note that the model prediction of the bent side plates and damaged bolts is in general agreement with the observed damage shown in the drop test photos.

The analysis also indicated that in the Stage Right 4-pack drops, the SI container will tend to tip toward its flange and the SI flange may hit the inside of the outer container as it compresses the shock-mitigation material surrounding the SI. The analysis showed that material directly surrounding the SI flange is subjected to higher impact loading than the material at the bottom of the container. This information was used during the design phase to match the shock mitigation material to the zone loading experienced in a typical drop.

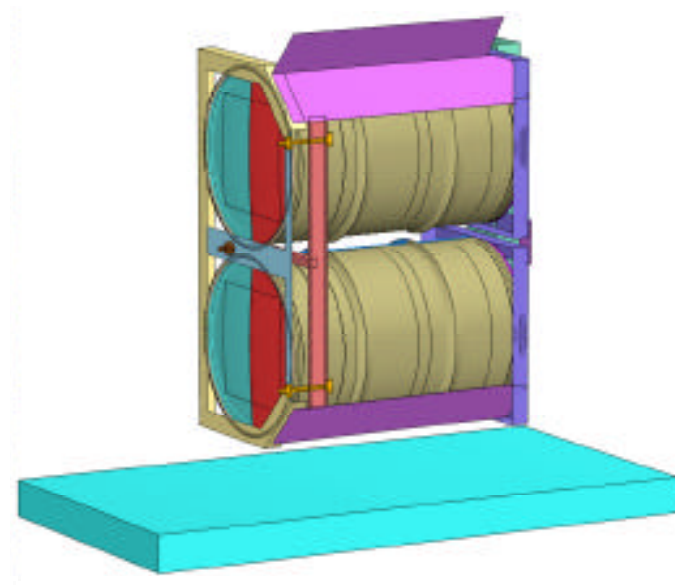

Figure 3.1.a Cross-section of a Stage Right 4-pack.

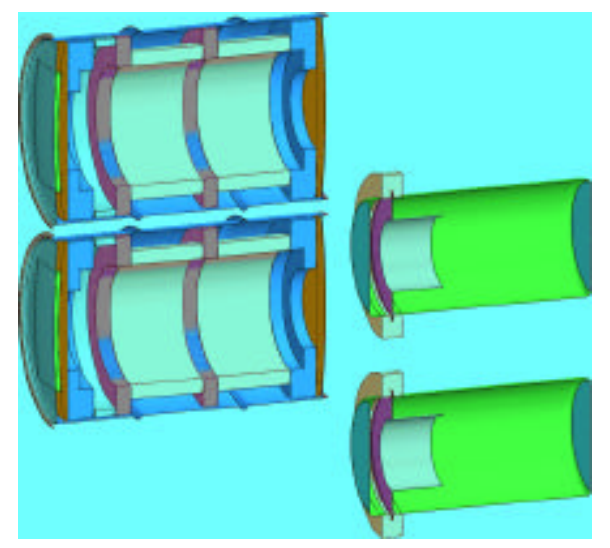

Figure 3.1.b Foam/cork container cross-section (with SI vessels removed for clarity). 
Using DYNA3D to simulate container performance prior to the experiment, it was possible to predict results and then make comparisons post-experiment. This led to a shorter design cycle and allowed evaluation of a wider range of variables than could have been done otherwise.

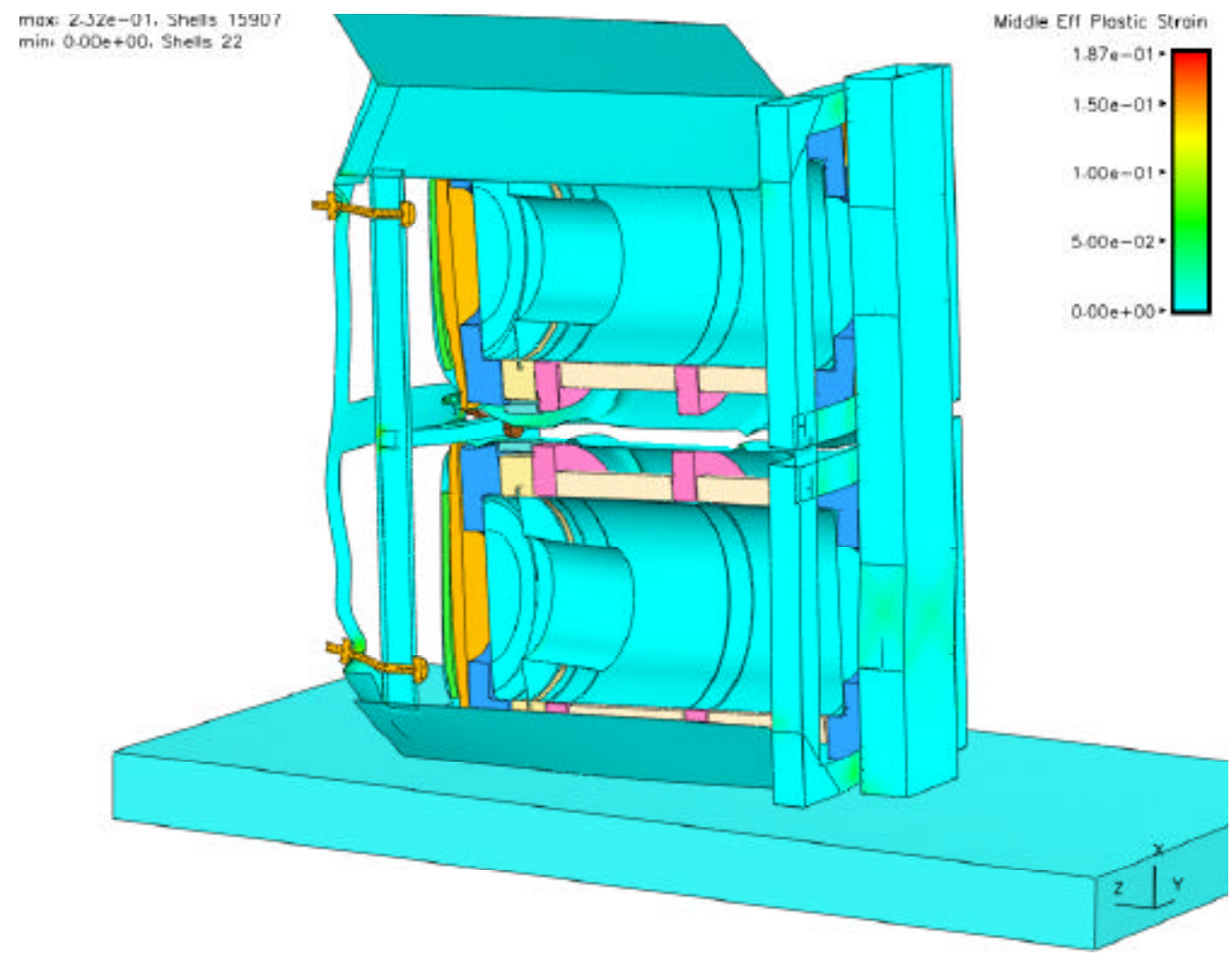

Figure 3.2.a Code prediction of post-drop condition for a foam/cork 4-pack 20-ft drop.

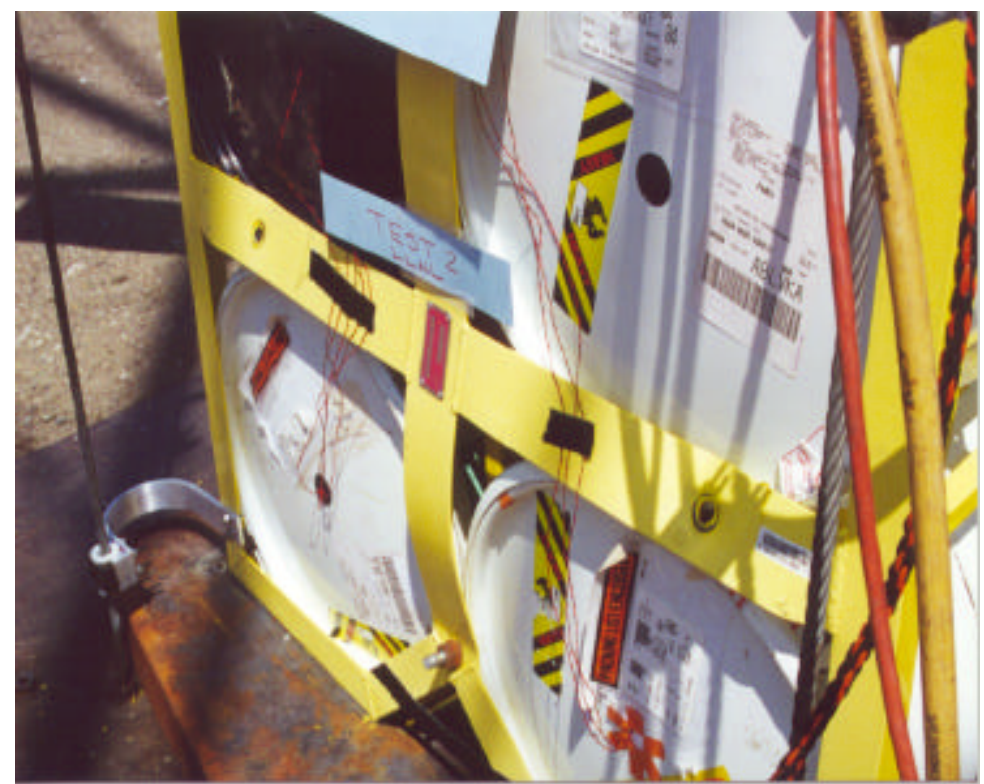

Figure 3.2.b AL-R8 SI foam/cork 4-pack after a 20-ft drop. 


\section{Thermal Analysis}

In addition to the 2D and 3D structural models, a 2D thermal model for the AL-R8 SI was created and used to evaluate the various design options (Stein 1999; Stein et al. 2000). The evaluation also used extensive data collected at Pantex and LLNL by the Thermal Working Group on the AL-R8 and AL-R8 SI containers. The data cover thermal performance of containers with real pits and mock pits in both stainless steel and carbon steel pit support fixtures, containers with argon and helium inert environments, and arrays of pit storage containers. There were several 2D thermal models used to evaluate the AL-R8 SI storage conditions and thermal insulation performance. The wealth of thermal data available made it possible to determine better estimates for several thermal coefficients that were used to tune and enhance the thermal modeling.

The evolved thermal model was helpful in the design phase because it allowed the insulation shape and thickness derived from the structural analysis to be thermally evaluated and the results fed back into the structural design. This iterative process was used to adjust materials and dimensions until the design met structural requirements and matched the Celotex thermal performance.

Figure 4.1 shows the location of the nodes used in the modeling and the corresponding Resistive Temperature Device (RTD) locations used during thermal testing. Figure 4.2 shows output from the thermal model for the AL-R8 SI container, illustrating the predicted temperature plots at various locations in and on the container. The results of thermal testing and comparison to predictions are discussed in Section 6.1 (Stein et al. 2000).

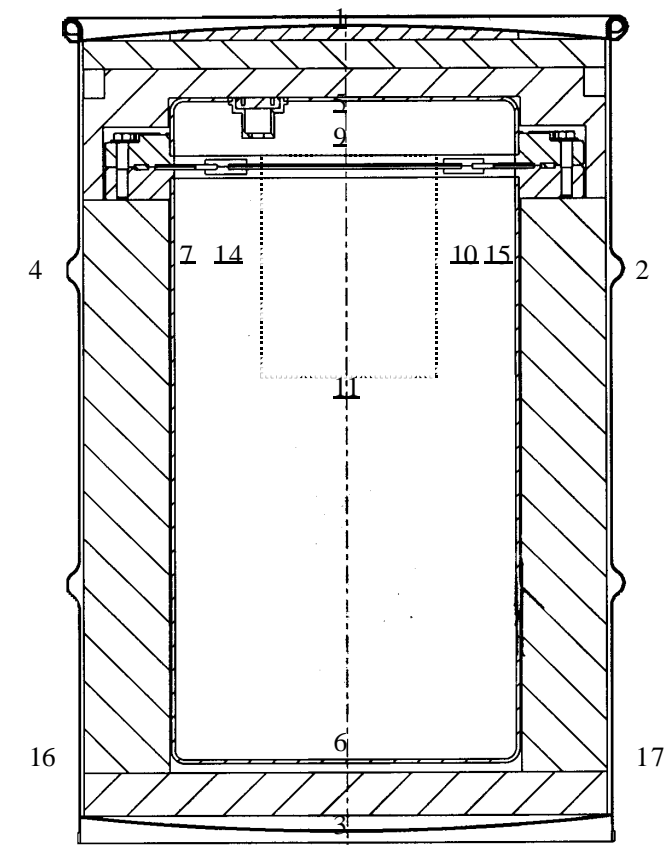

Figure 4.1 Drawing of AL-R8 SI showing locations of the RTDs for thermal modeling and testing. 

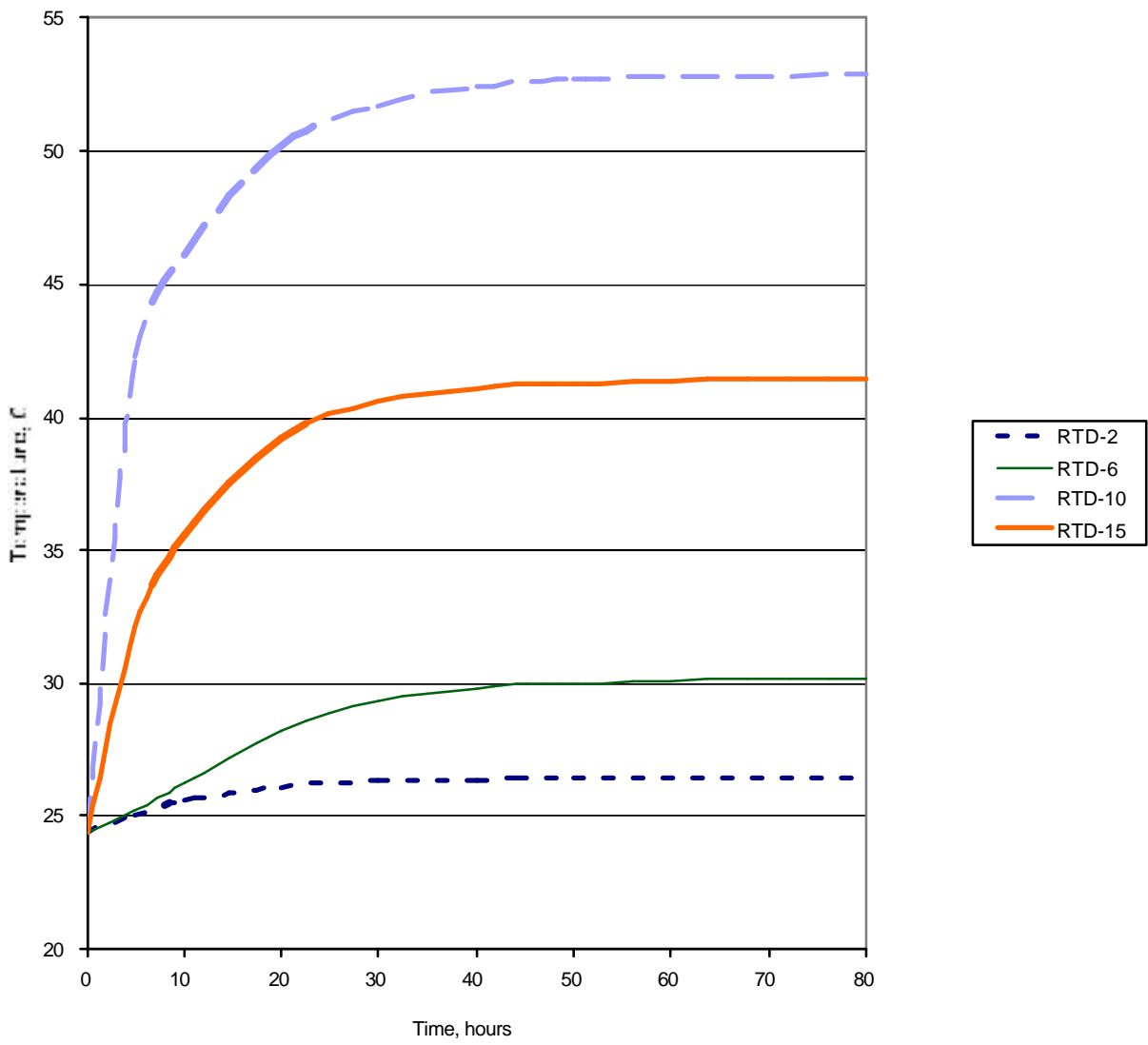

Figure 4.2 Model predictions for temperatures at RTD locations 2, 6, 10, and 15 for a container with Celotex. 


\section{Container Design}

AL-R8 SI container designs incorporating the new insulation/shock mitigation materials are shown in Figures 5.1.a and 5.2. The new designs divide the container into three zones: the top and bottom zones perform the shock mitigation function, while the middle zone dissipates the heat in the normal storage condition and protects the package from thermal incursions during accident conditions.

\subsection{Foam Design}

The foam insulation packaging design derived from the structural and thermal analysis is shown in Figure 5.1.b. (Engineering drawings of this design are shown in Appendix A.) The foam used in this design is GP FR-3700, which is a closed-cell, rigid polyurethane foam specifically formulated as a shock mitigation and insulating material for nuclear material shipping containers. The GP FR-3700 material is currently being used in other radioactive material shipping containers such as the AL-SX (H1616), MH-2800, AT-400A, AT-400R, and Trupac II.

The design utilizes low-density foam (GP FR-3715) for the shock mitigation areas around the SI flange and at the top and bottom of the drum. The low-density foam better attenuates shocks, reducing the transmission of container vibration and shock to the SI and its contents. However, since the low-density foam also has a low thermal conductivity, it would negatively impact the thermal performance of the container if used exclusively as the insulation/shock mitigation material. Instead, the high-density foam (GP FR-3730) - which has a higher thermal conductivity and performs better as thermal insulation and fire retardant - is used in the center of the drum. The use of two different foam densities allowed the design to be adjusted to achieve all of the performance objectives.

The 30-pound foam insert outer diameter is smaller than the steel drum inner diameter. This creates a large air space between the foam and the sides of the container as shown in Figure 5.1.a. The air space greatly increases heat transfer compared to the thermal resistance of the Celotex along the sides of the container.

\subsection{Foam/Cork Design}

The design shown in Figure 5.2 is an alternate to the all-foam design and replaces the low-density foam with cork. The top and bottom insulation sections are hollow in the center to improve the thermal performance. A band of cork has also been added at the middle of the drum to enhance shock mitigation and reduce the $g$-loading on the pit. In a drop test scenario using this design, the foam and a thermal insulating barrier, i.e., a Fiberfrax ${ }^{\circledR}$ ceramic alumina-silica insulating blanket on the top of the cork, provided the necessary restraint to prevent the SI from tipping during the impact and transmit some of the forces directly to the drum cover. The foam surrounding the SI flange absorbs the balance of the shock and prevents the SI sealing flange from contacting the outer drum.

The cork material has excellent shock mitigation properties and good thermal and fire resistance. Cork is the primary shock mitigation and insulation material for the LANL SAFKEG 2863B Package, which is designed to store and ship fissile materials. The disadvantage of using cork material is the higher cost and increased weight of the total package.

Modeling of the temperature response of the containers with the new materials predicts that pit temperatures would be close to equal for the three types of insulation material. 


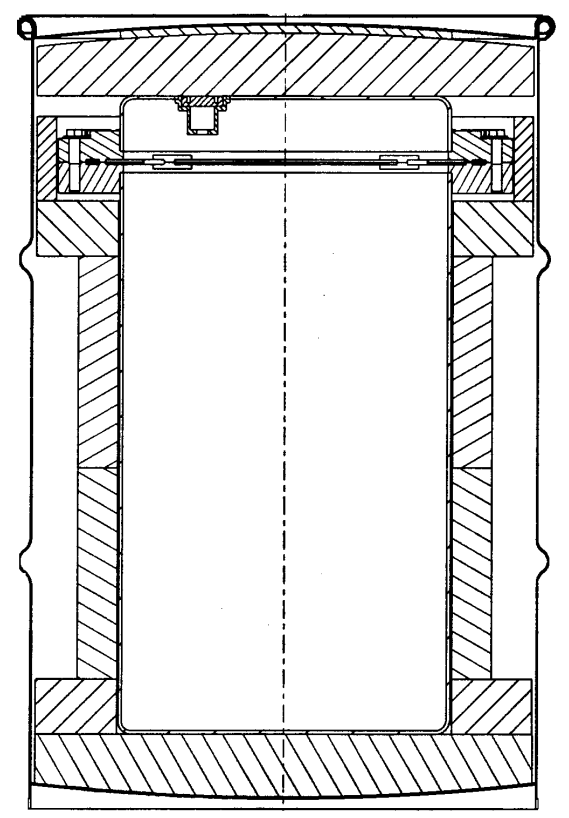

Figure 5.1.a AL-R8 SI with foam inserts.

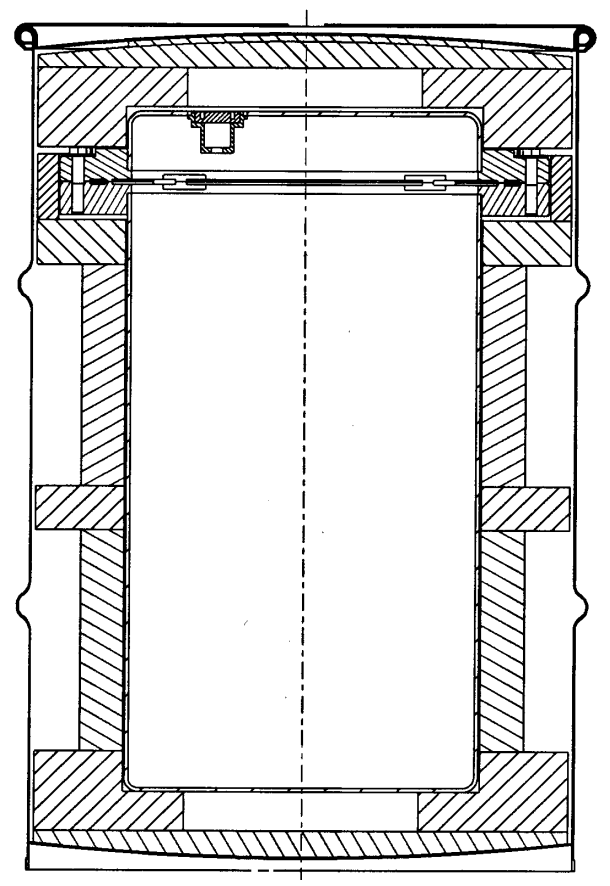

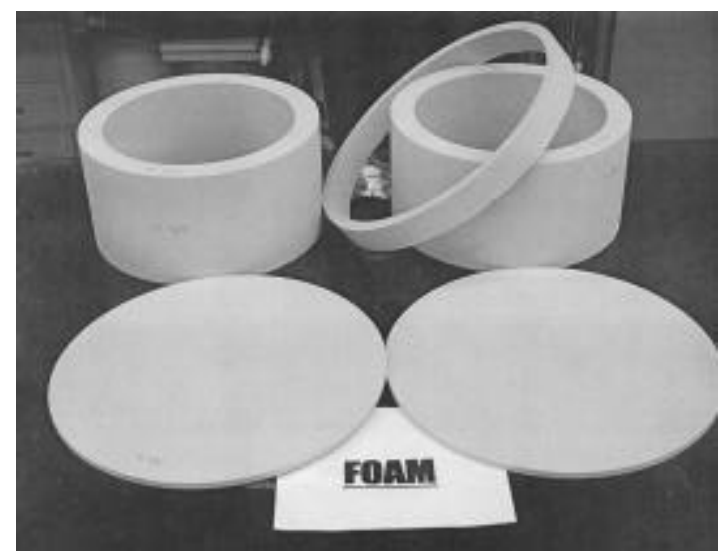

Figure 5.1.b Foam inserts.

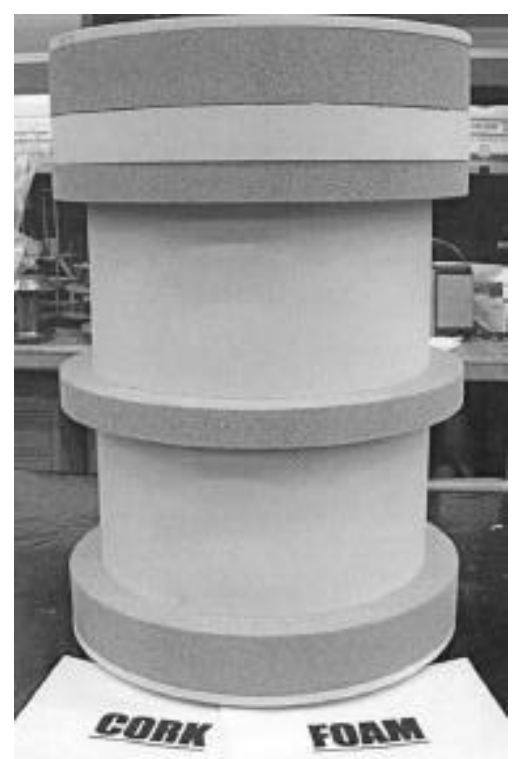

Figure 5.2 AL-R8 SI with foam/cork inserts. 


\section{Qualification Testing}

Qualification testing was performed to validate the new material and to demonstrate that it performs as well as Celotex. Test plans were developed based on the SI qualification test criteria (Addington 2000b). The containers used for testing were provided to LLNL by Pantex and configured like the AL-R8 SI production units. For most tests, an AL-R8 SI container with Celotex was used as the benchmark for evaluating the new material performance. Testing included thermal equilibrium tests, 20 - $\mathrm{ft}$ drop tests of pallets, 4 ft drop tests of containers, and a comparative vibration test to alleviate concerns about vibration transmission to the contents.

\subsection{Thermal Testing}

To meet the thermal criteria for pit storage, containers must protect the pit from exceeding its storage temperature limits by conducting the heat away from the pit and into the cooler environment. The container should also protect the pit in the hypothetical accident scenario from shock and heat flux generated by fire. Celotex thermal performance, however, depends to a degree on the moisture content and temperature with the thermal conductivity varying between 0.053 to $0.074 \mathrm{~W} / \mathrm{m} \cdot \mathrm{K}$. Polyurethane foam, on the other hand, has a thermal conductivity that is practically stable at various humidity levels.

To demonstrate the thermal performance of the foam and foam/cork designs, Celotex and foam designs were evaluated under simulated storage conditions. The thermal test was conducted in a sequential order, using the standard AL-R8 SI, first with Celotex, then the foam, and finally a combination of foam and cork.

The thermal test used a mock pit with an electrical heater to simulate the thermal loading from a real pit, and the temperature was measured across the various layers of the container. This was done at a nominal ambient temperature of about $75^{\circ} \mathrm{F}$ (Stein et al. 2000).

Test Configuration. The test container configurations are shown in Figure 1.1, 5.1.a, and 5.2. The container and the insulation material were placed in the test laboratory at least 48 hours prior to the test to ensure the package reached thermal equilibrium before the start of the test. An electrically heated mock pit mounted in a stainless steel fixture was used to simulate the real pit. The mock pit heat output was set to the same output used in previous SI qualification tests (Foster et al. 1999). The tests were conducted on containers in both vertical and horizontal orientations for each type of insulation material.

The thermal experiments on the three types of materials demonstrated that the three configurations performed as predicted by the thermal model. The experiments validated that the thermal design for the foam and foam/cork geometries closely matched the thermal performance of the Celotex baseline. Figure 6.1 is a plot of the temperature difference between the pit surface and ambient temperature for the three test cases. The data were derived from Stein et al. (2000). The traces for all three are almost identical. 


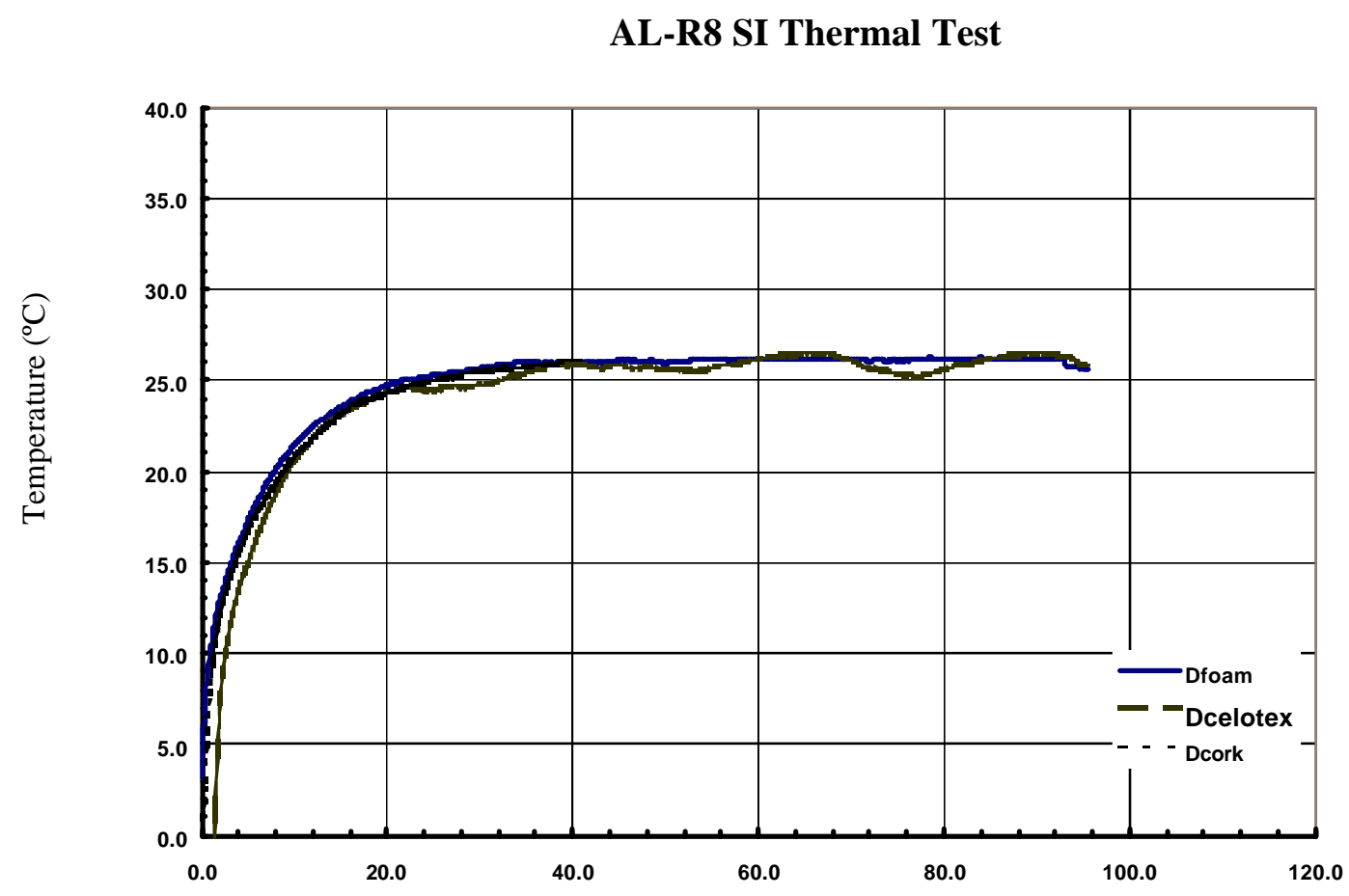

Time (hours)

Figure 6.1 Pit temperature above ambient for Celotex, foam, and foam/cork materials.

\subsection{Drop Testing}

\subsubsection{0-ft Drop Test}

Test Description. This test was designed to evaluate the performance of the container and its shock mitigation properties during an accidental drop from a 20 - $\mathrm{ft}$ height. The container was assembled, leakchecked and mounted in a standard Stage Right 4-pack configuration as shown in Figure 6.2. The 4-pack was lifted to a 20 -ft height, then dropped on an unyielding surface $\left(48^{\prime \prime} \times 48^{\prime \prime} \times 4\right.$ " thick steel plate on concrete). The test apparatus was designed to ensure that the pallet impacted the target plate with the bottom of the pallet parallel to the target plate. After the drop, the 4-pack was photographed and inspected for damage; the containers were removed and the SIs were leak-checked to see if they met the $1 \times 10^{-}$ ${ }^{7} \mathrm{cc} / \mathrm{s}$ (air) $)_{\mathrm{sp}}$ leak-check criteria. Results of the drop test are reported by Woelffer (2001).

In addition to demonstrating that the container could meet the drop test and leak-check requirements, the test was also designed to obtain design information on the materials' shock mitigation response and configuration in order to compare the new material performance to Celotex. To obtain this additional information, accelerometers were attached to the two test containers to monitor the new material performance.

In addition to the accelerometers, a high-speed camera and background target were used to record the impact of the pallet and estimate the speed and elevation of the pallet and drums in the vicinity of the impact zone. 
Test Unit Configuration. The drop test was conducted on three Stage Right 4-pack pallets pictured in Figures 6.3, 6.4, and 6.5. Two pallets were from Pantex and one from LLNL. In each pallet, the top two drums provided a dummy load to simulate the weight of loaded AL-R8 SI packages so impact loads would be representative. The bottom drums were designed to meet particular test objectives.

The two pallets from Pantex, Pallet \#1 and Pallet \#2 shown in Figures 6.3 and 6.4, were designed to qualify an Alloy 718 bolt to replace the carbon steel bolt used to secure the SI lid. They were also used to test the performance of the carbon steel birdcage fixture in the SI. The Pantex pallets were assembled, checked, and leak-tested at Pantex, then shipped to LLNL. The detailed configuration of the Pantex drums will not be discussed here since LLNL was not involved in their configuration.

Several accelerometers were attached to the LLNL test containers to monitor the new material performance and two were attached to one of the Pantex containers to obtain the reference data for Celotex.

The high-speed camera allowed the impact angle to be verified and provided an independent measure of the container acceleration. The camera speed was set to 1,000 frames/second and it was triggered to begin recording at the same time as the bomb release was actuated on the drop tower. During the first and second tests, the camera was focused on the center area of the pallet and the target steel plate (see insert (A), Figure 6.7). During the third test, the camera was moved to focus on the right corner of the pallet (see insert (B), Figure 6.7) to improve background target lighting. The background target was made from a cardboard sheet placed on a sheet of plywood and attached to a self-supporting wood frame. The target was marked using one-inch-wide tape spaced one inch apart (see Figure 6.5).

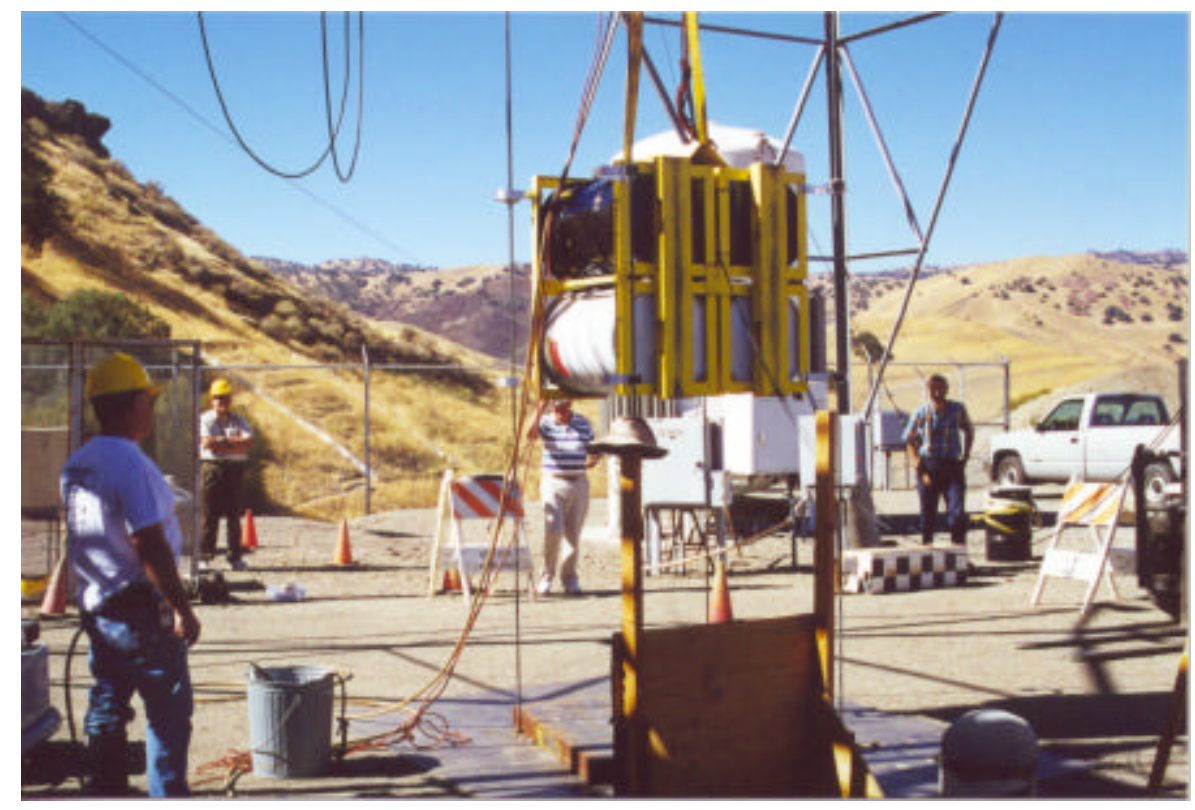

Figure 6.2 Preparing for the 20-ft drop test at the 100-ft drop tower at LLNL Site 300 .

The third pallet, pictured in Figure 6.5, was assembled by LLNL in Livermore from containers and pallets shipped from Pantex. It was designed to qualify the foam and foam/cork candidates as replacements for Celotex in the AL-R8 SI. 


\section{$\underline{\text { LLNL Container \#1 Configuration }}$}

Container \#1 was assembled using:

- a stainless steel birdcage fixture with a dummy load to simulate payload,

- two accelerometers mounted on the fixture at 0 degrees and 180 degrees to the drop,

- an SI vessel,

- the SI lid supplied by SANDIA/Livermore Laboratory with electrical feed-through for the accelerometer wiring,

- three additional accelerometers mounted on the SI flange, two mounted at 0 degrees on the top and bottom flanges and one mounted at 180 degrees at the top flange (see Figure 6.6),

- foam/cork inserts,

- the Fiberfrax package, and

- a 30-gal AL-R8 drum.

\section{$\underline{\text { LLNL Container \#2 Configuration }}$}

Container \#2 was assembled using:

- a stainless steel birdcage fixture with a dummy load to simulate payload,

- an SI vessel,

- a matching SI lid,

- three accelerometers mounted on the SI flange, two at 0 degrees on the top and bottom flanges and one mounted at 180 degrees on the top flange,

- foam inserts,

- a Fiberfrax package, and

- a 30-gal AL-R8 drum.

Both containers were leak-checked before and after the test and confirmed to meet the

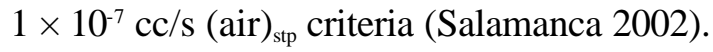

The Stage Right pallet was oriented to provide a flat drop onto the side of the containers as would occur if the containers were loaded in the Stage Right 4-pack configuration and the pallet was dropped onto its base. The 20 -ft drop tests are designed to obtain the same impact orientation and impact velocity for all pallets to facilitate data comparison. The tests were conducted at the Building 856, 100-ft Drop Tower at Site 300, LLNL. 


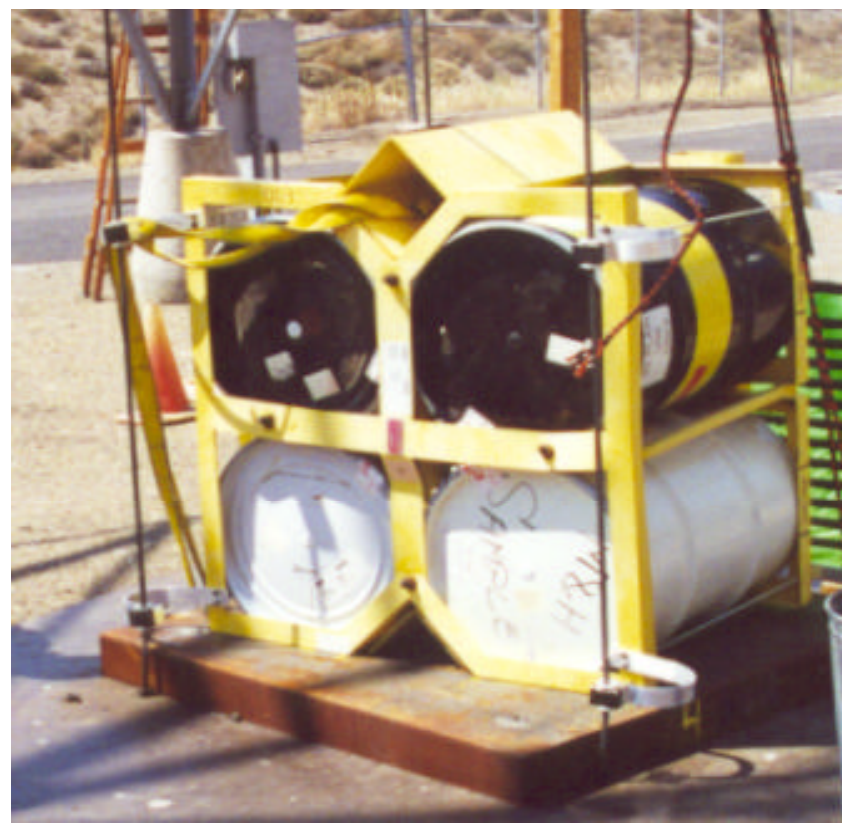

Figure 6.3 Pantex Pallet \#1 after the drop test. (Unit 12228-6-562 used to test the carbon steel fixture as required by Pantex 706035.)

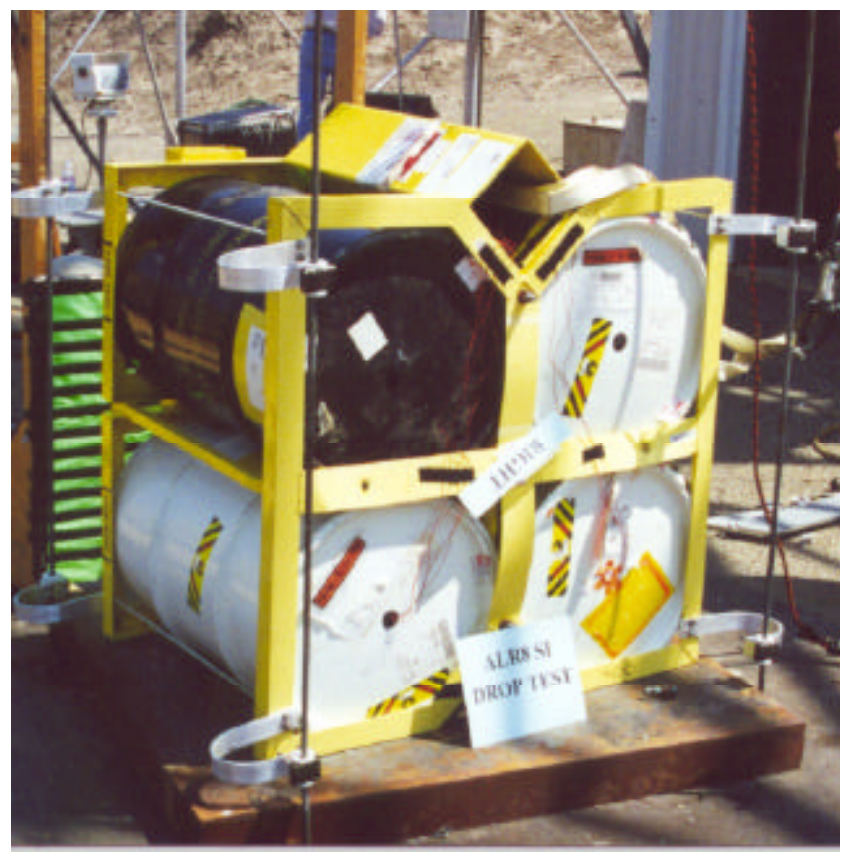

Figure 6.5 LLNL 4-pack Pallet \#1 after the drop test. (The LLNL pallet was configured to test the foam and the foam/cork materials.)

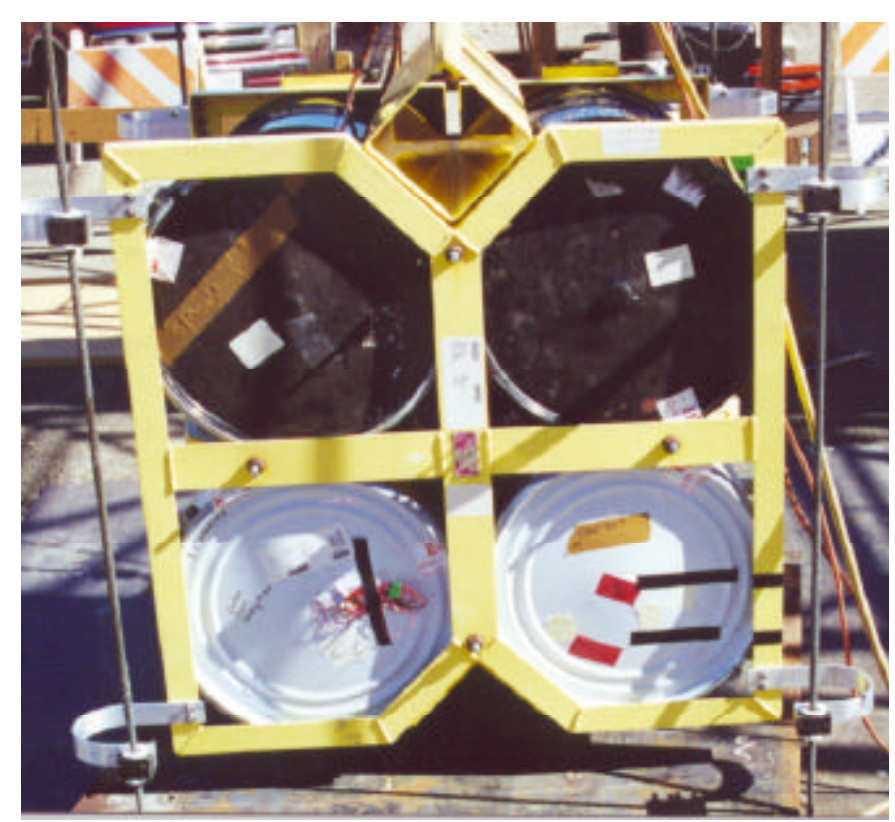

Figure 6.4 Pantex Pallet \#2 ready for the drop test. (Unit 12228-7-297 used to qualify the new 718 Alloy bolts and provide accelerometer data for Celotex.)

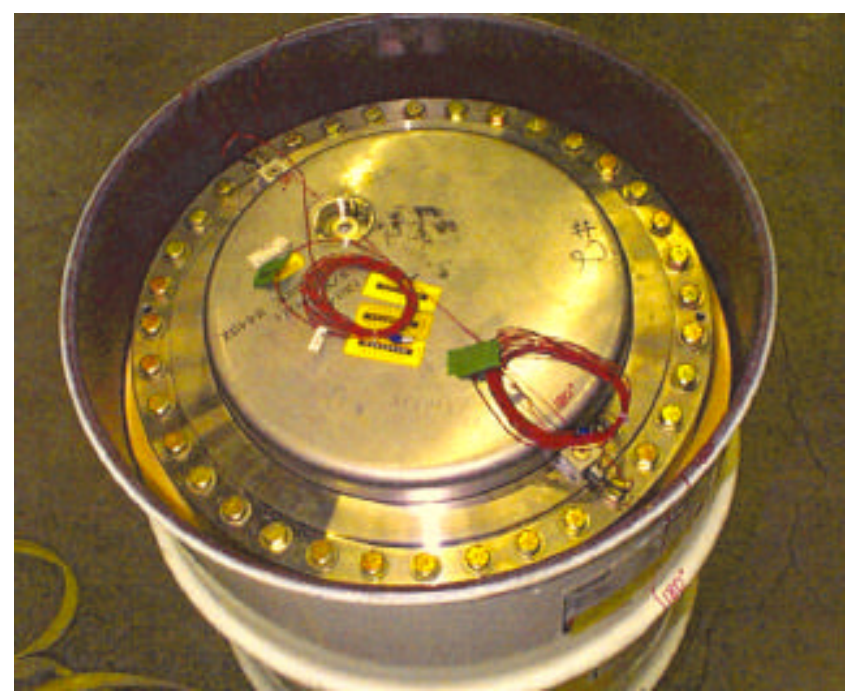

Figure 6.6 Accelerometer locations on the SI flange (top shown) for the foam container. 


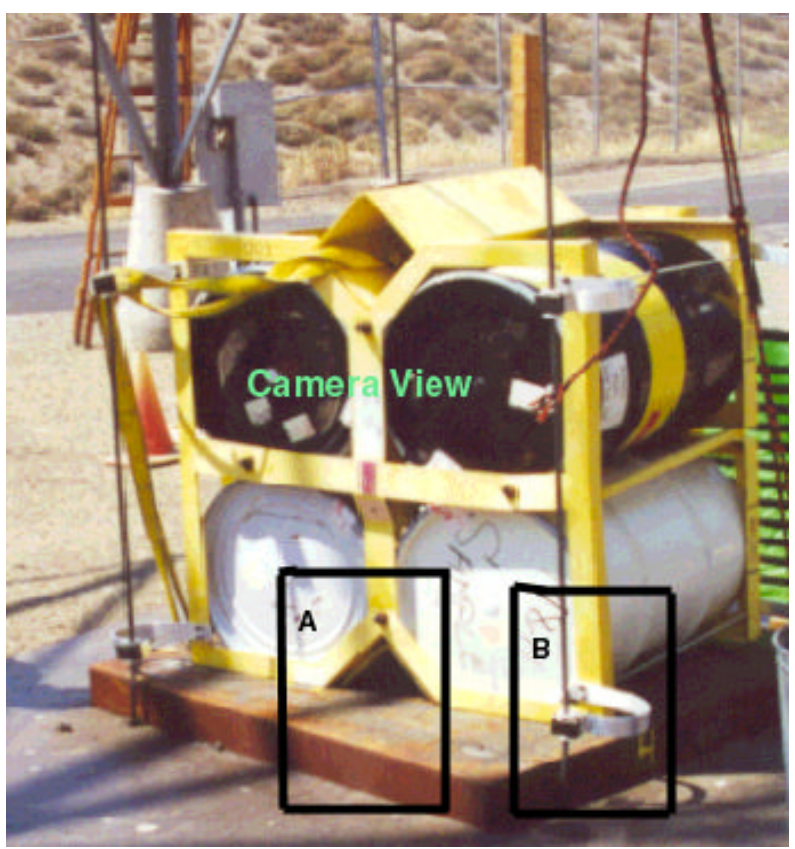

Figure 6.7 High-speed camera field of view for drop tests 1 and 2 (A) and test 3 (B).

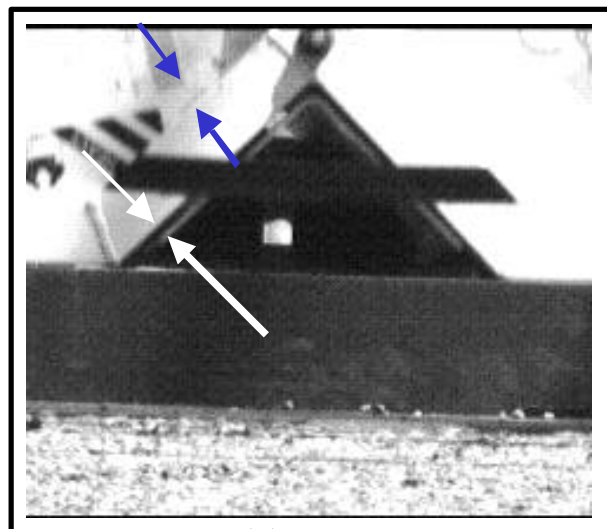

(a)

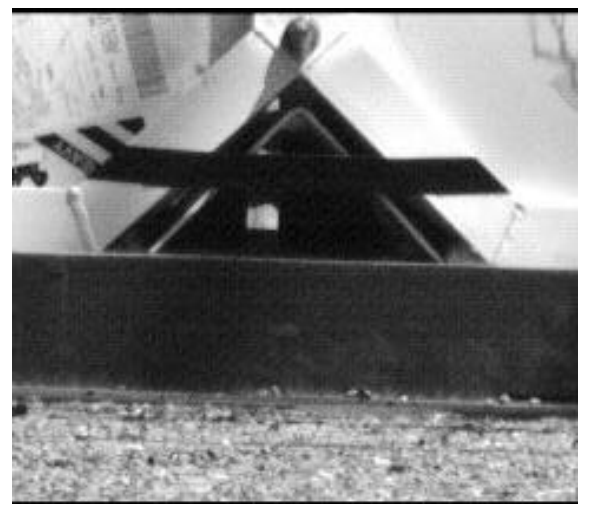

(c)

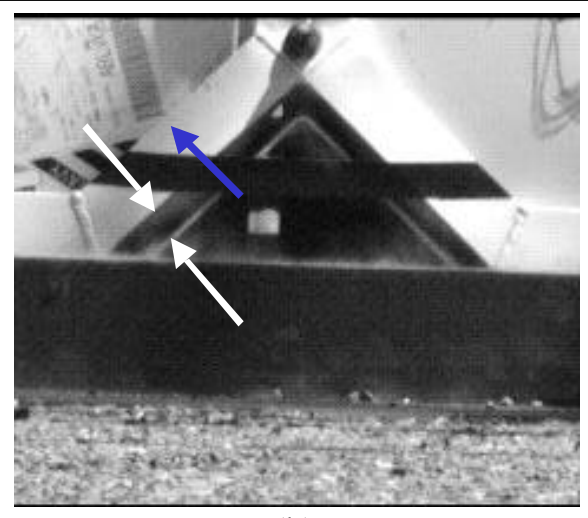

(b)

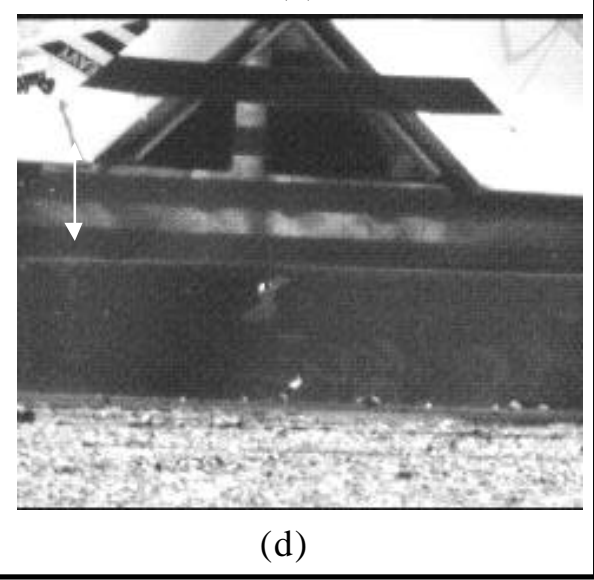

Figure 6.8 High-speed camera frames showing: (a) pallet first contact with the target plate, (b) pallet deflection due to impact, (c) end of downward motion, and (d) first rebound. 
Figure 6.8 shows several frames from the first drop test (Pantex Pallet \#1). Frame (a) shows the pallet at the moment of impact on the steel plate. This picture shows that the pallet frame was parallel to the impact target as intended. Frame (b) shows the amount of deflection in the pallet as the impact force increases. Frame (c) shows the pallet as it is leaving the plate on the rebound, and Frame (d) shows the height of the rebound. The arrows in the photo-frames indicate the relative motion of the steel drum in relation to the pallet frame.

The high-speed camera data provided a timed reference guide for the impact data collected from the accelerometers. Figure 6.9 shows the relation between the motion of the pallet and the drum in the lower left side of the 4-pack pallet. Here the time from impact to rebound is approximately the same as the data taken from the accelerometers in tests 2 and 3.

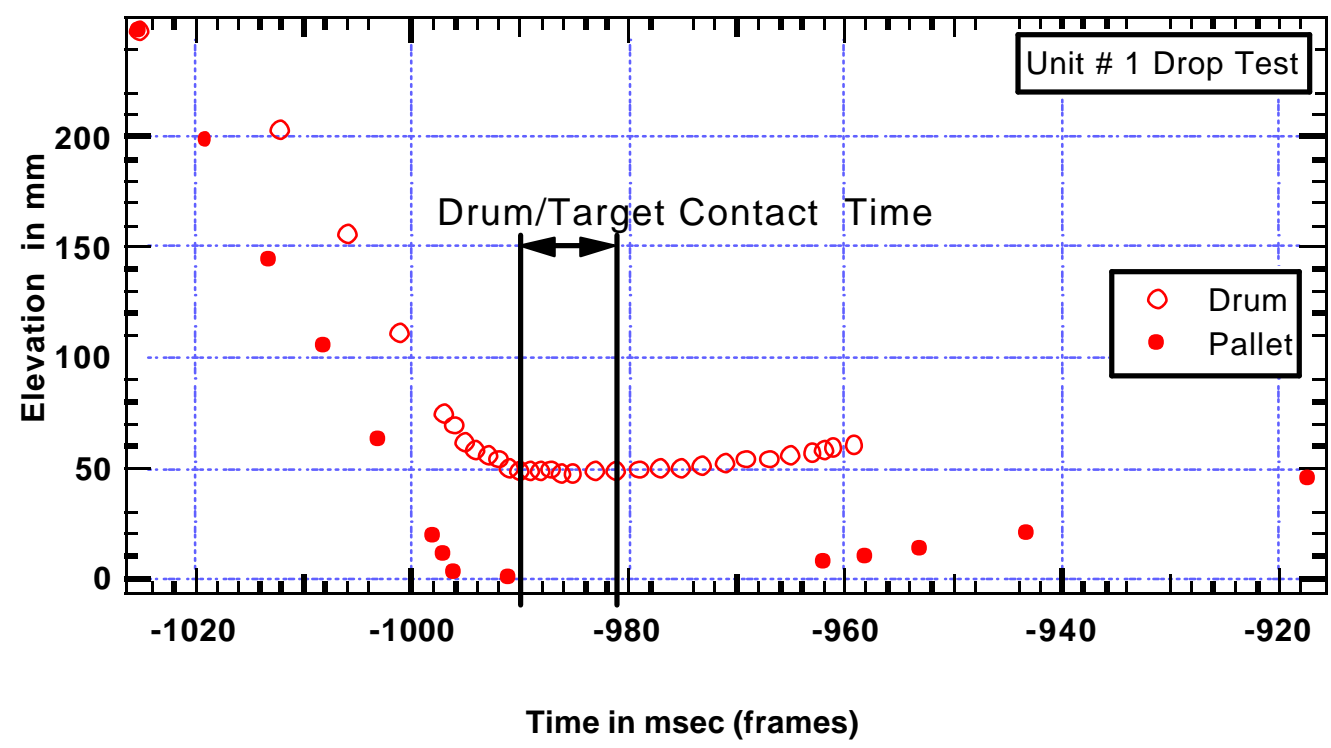

Figure 6.9 Data from high-speed camera frame analysis for the Pallet \#1 drop test.

20-ft Drop Test Results. The steel pallet (Stage Right pallet) sustained severe damage in all three tests. The bolts holding the pallet cover to the pallet were bent severely. In one case, they sheared and fell down next to the pallet. The location of these bolts makes them vulnerable to the impact of the upper drums in a vertical drop. The two lower drums suffered the most damage from the impact, as expected. In all cases, the steel drum lid hoop and the lid were bent, but the lid stayed in place. The outer drum was flattened by about 2 in. at the area of impact (see Figure 6.10). 


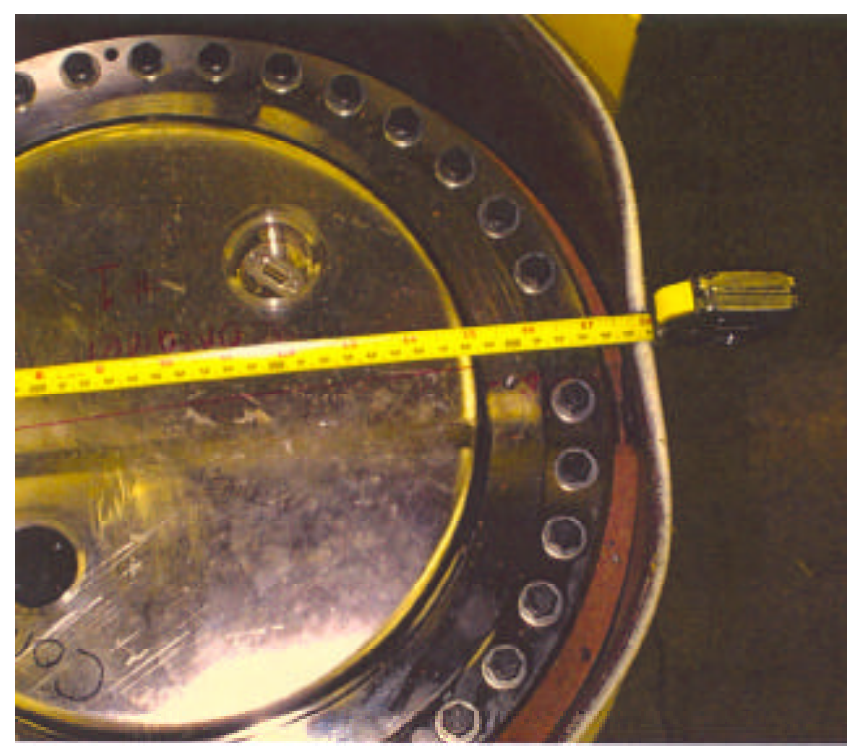

Figure 6.10 Container after the 20-ft drop test (steel drum deformed from impact).

Inspection of the foam and foam/cork insulation material around the SI showed little damage. While the SI inside the foam (container \#2) showed no marking from the impact, the SI in the foam/cork container (container \#1) showed a mark from contacting the drum seam weld. There was no indication from the SI exterior that the dummy load hit the side of the SI container. Examination of the fixture after SI disassembly showed that the dummy load shifted slightly and, in turn, bent the fixture lower plate (see Figure 6.11).

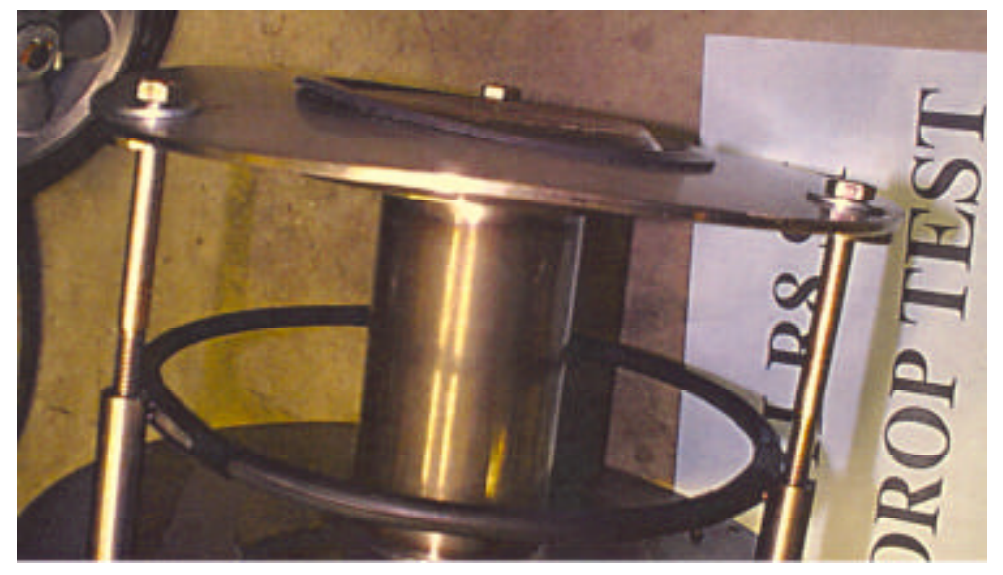

Figure 6.11 Stainless steel fixture after the $20-\mathrm{ft}$ drop. (Notice the bent lower plate.)

Table 6.1 compares the $g$-loads recorded during impact for the Celotex, foam, and foam/cork designs. Figure 6.12 shows the unfiltered accelerometer data from tests of these container designs. Figure 6.13 shows the filtered accelerometer data. Celotex shows similar $g$-loads to the foam while the foam/cork setup shows the lowest average value. Post-test evaluations, however, showed that the cork yielded enough to allow the SI flange to touch the outer steel drum seam weld, which explains the ringing in the accelerometer trace (see Figure 6.12, output screens BE25 and BE23). The weld was unusually large in this particular drum compared to other drums, and will be reviewed to see if it is within the drum specification. 
Table 6.1 Accelerometer data (average) for the 20-ft drop test.

\begin{tabular}{|l|c|c|}
\hline Material/Position & 0 Degrees & 180 Degrees \\
\hline Celotex & $500 g$ & $300 \mathrm{~g}$ \\
\hline Foam & $380 \mathrm{~g}$ & $400 \mathrm{~g}$ \\
\hline Foam/Cork & $250 \mathrm{~g}$ & $250 \mathrm{~g}$ \\
\hline
\end{tabular}

After the drop test, the LLNL SIs were leak-checked in Livermore and the Pantex SIs were returned to Pantex to complete their testing. Both the foam and foam/cork containers were confirmed to meet the $<1 \times 10^{-7} \mathrm{cc} / \mathrm{s}$ (air) $)_{\mathrm{stp}}$ criteria (Salamanca 2002).
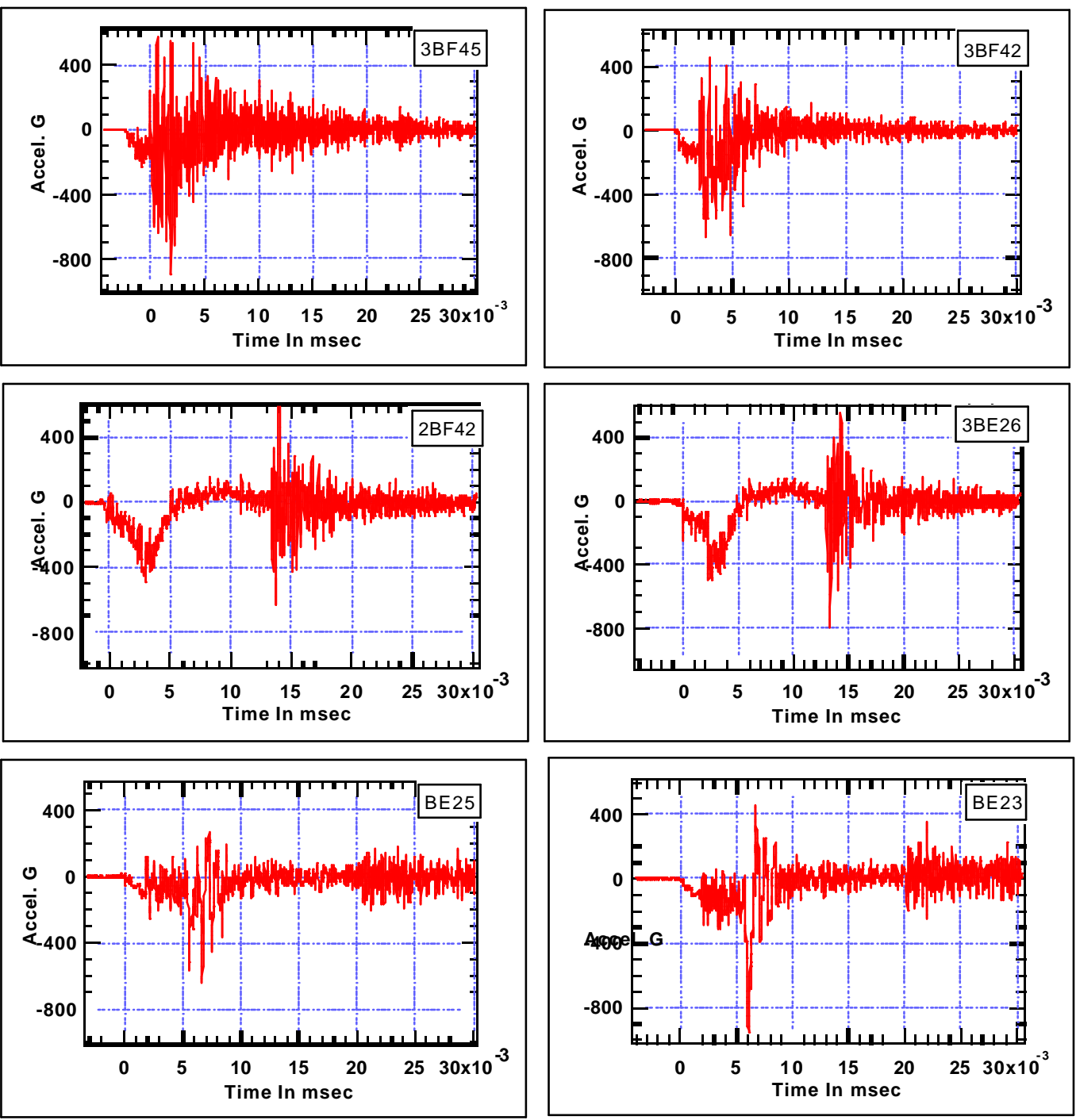

Figure 6.12 Unfiltered accelerometer data from drop tests with foam and foam/cork insulation. Accelerometer output-unfiltered; 0 degree left trace, 180 degree right trace; top-Celotex; middle-foam; bottom-foam/cork. 


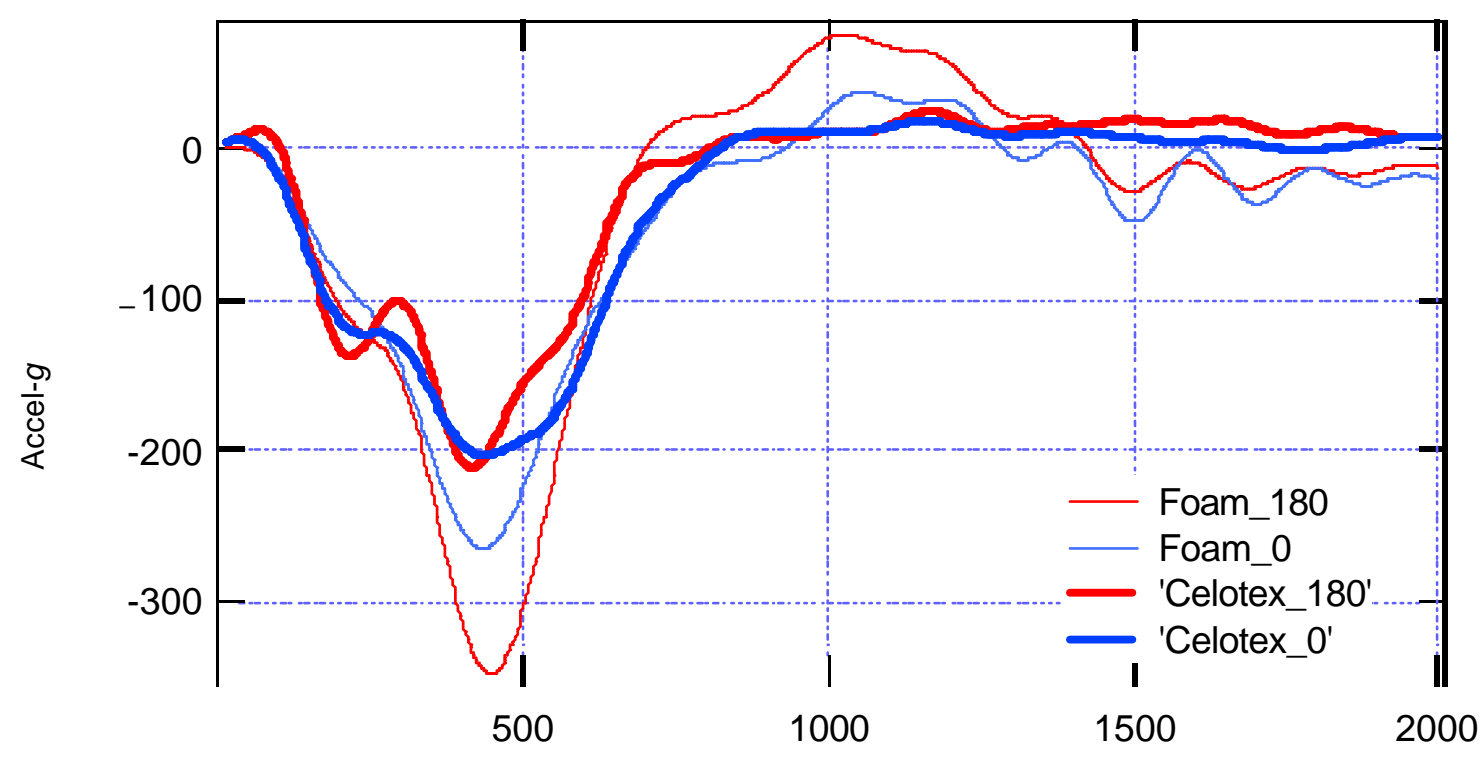

Time in msec

Figure 6.13 Filtered accelerometer data.

\subsubsection{4-ft Drop Test}

The 4-ft drop test was performed to validate the insulation designs for a 4-ft handling drop of a bare container.

\section{LLNL 4-ft Drop Configuration}

The bare container was assembled using:

- a stainless steel fixture with a dummy load to simulate payload,

- an SI vessel,

- a matching SI lid,

- foam inserts,

- a Fiberfrax blanket (package), and

- a 30-gal AL-R8 drum (supplied by Livermore).

The SI was assembled with a stainless steel fixture and dummy load and then leak-checked. The SI was assembled in the AL-R8 drum using foam inserts and the Fiberfrax blanket. The container was laid flat on the target steel plate. The container was then lifted to a 4-ft height using straps that ensured the drum stayed parallel to the target plate before the drop (see Figure 6.14). The test was conducted at LLNL Site 300 . 
Visual inspection of the drum exterior following the drop showed very little damage to the container. The steel drum was flattened slightly at the impact area. The container was disassembled and the SI was removed for inspection and leak-checked. The leak-check confirmed that the SI met the $<1 \times 10^{-7} \mathrm{cc} / \mathrm{s}(\text { air })_{\mathrm{stp}}$ criteria.

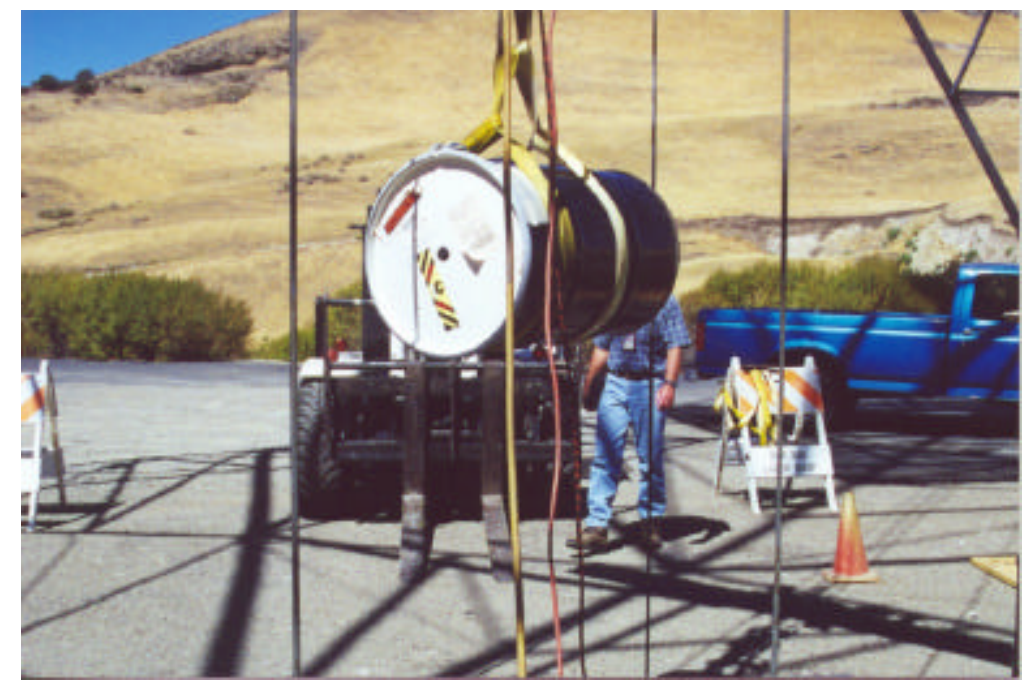

Figure 6.14 4-ft drop test.

\subsection{Vibration Testing}

The vibration test requirement for the AL-R8 SI is intended to ensure that the new container does not propagate the vibration encountered during transportation to the payload. The test is set up as a comparative test between the SI with Celotex, the SI with foam, and the FL container. To qualify the foam as an alternative material for the AL-R8 SI, the test was conducted at the LLNL vibration laboratory using the SST vibration spectrum listed in the WYLE Labs report (Porter 1999).

The test container was assembled in the AL-R8 SI configuration except for replacing the Celotex with foam and adding accelerometer cables.

\section{$\underline{\text { Configuration of Vibration Test Container }}$}

The Vibration Test Container was assembled using:

- a stainless Steel birdcage fixture with a dummy load to simulate payload,

- two accelerometers mounted on the fixture at 0 and 180 degrees from the drum weld seam,

- an SI vessel,

- an SI lid supplied by SANDIA/Livermore Laboratory with electrical feed-through for the accelerometer wiring,

- foam inserts,

- a Fiberfrax package, and

- a 30-gal AL-R8 drum. 
The SI was leak-checked before it was inserted into the drum. The vibration fixture supplied by Pantex was mounted to the shaker table and the assembled container was then tied down to the fixture in the same manner as used in the Safe Secure Transport. The container was then subjected to random vibration from 10 to 2,000 Hz for 60 minutes. The accelerometer data were recorded and the power spectra for each accelerometer were plotted. Table 6.2 summarizes the output from the vertical axis of the accelerometer in comparison to the results for the FL and SI containers.

Table 6.2 Summary of vertical vibration from the 3-axis accelerometer.

\begin{tabular}{|l|c|c|c|c|c|c|c|c|}
\hline $\begin{array}{l}\text { Accelerometer/ } \\
\text { Container }\end{array}$ & $\mathbf{1 0 ~ H z}$ & $\mathbf{2 0 - 3 0 ~ H z}$ & $\mathbf{7 0 ~ H z}$ & $\mathbf{8 0 - 1 0 0 ~ H z}$ & $\mathbf{6 0 0 ~ H z}$ & $\mathbf{7 0 0 ~ H z}$ & $\mathbf{1 , 2 0 0 ~ H z}$ & $\mathbf{2 , 0 0 0 ~ H z}$ \\
\hline FL & $2 \times 10^{-4}$ & $3 \times 10^{-4}$ & $1 \times 10^{-4}$ & $5 \times 10^{-4}$ & $1 \times 10^{-8}$ & $1 \times 10^{-8}$ & $1 \times 10^{-8}$ & $1 \times 10^{-4}$ \\
\hline AL-R8 SI & $2 \times 10^{-4}$ & $6 \times 10^{-3}$ & $1 \times 10^{-4}$ & $5 \times 10^{-5}$ & $1 \times 10^{-8}$ & $1 \times 10^{-8}$ & $1 \times 10^{-8}$ & $1 \times 10^{-8}$ \\
\hline AL-R8 SI Foam & ----- & $5 \times 10^{-4}$ & $8 \times 10^{-5}$ & $6 \times 10^{-5}$ & $5 \times 10^{-7}$ & $2 \times 10^{-7}$ & $2 \times 10^{-7}$ & $5 \times 10^{-8}$ \\
\hline
\end{tabular}

After the test, the container was removed and disassembled and the SI was then sent to the vacuum laboratory for a leak-check. The leak-check showed the container leak rate met the $\left.<1 \times 10^{-7} \mathrm{cc} / \mathrm{s} \mathrm{(air)}\right)_{\mathrm{stp}}$ criteria. 


\section{Post-Test Analyses}

Both the foam and foam/cork designs performed acceptably during preliminary analysis and qualification testing. To ensure there were no outstanding issues with either replacement material, shielding, criticality, and fire analyses were performed to complete the testing.

\subsection{Shielding Analysis}

A comparison of the dose rates for normal conditions of transport (NCT), based on 10 CFR 71.47 and 10 CFR 71.51, was made based on a worst-case generic pit (Hansen 2000). The choice of the generic pit was discussed in detail in the Shielding Report for the AL-R8 SI qualification analysis. The MCNP code (LANL 1997b) calculation was done using the drawing of the container with the Celotex overpack and the foam/cork overpack. The dose rate was calculated at points $1-\mathrm{cm}$ and 1-m from the surface over an area of 1-cm radius. The composition of the foam and cork was taken from the chemical analysis of these materials carried out by the LLNL Chemistry and Material Science Division (Heinrichs 2000).

Overall, the foam/cork overpack does a better job than Celotex. However, at the sidewall of the container, the dose is slightly higher than for Celotex due to the reduced material thickness. This higher dose is still below the maximum allowed by 10 CFR 71.47 .

\subsection{Criticality Analysis}

The criticality safety evaluation report for the AL-R8 SI (Troyer 1997), shows that the AL-R8 SI configuration meets the criticality safety requirements for safe storage at Pantex. The criticality safety evaluation was done under NCT and hypothetical accident conditions (HAC). The material properties, geometry, and payload all play an important factor in the analysis. The report concludes that the addition of stainless steel, which is a neutron absorber, improves the SI performance slightly over the original AL-R8. In addition, the SI itself provides advantages in the case of a fire, since the SI metal shell and flange will assist in centering the pit inside the outer drum, reducing the amount of change in the geometry of the array after the fire. The performance of the container with the SI (with Celotex, foam, or cork) will be slightly better than the original AL-R8 container in an accident scenario.

In his review comments on the criticality safety evaluation report (Troyer 1997), Heinrichs noted a number of deficiencies, in particular that the analysis was based on a preliminary design and one particular pit (Heinrichs 1999). That caution applies equally here since the criticality analysis below is based on comparisons of materials and not final container designs. Precise comparisons are straightforward but would require final design details.

Material density and the hydrogen and carbon content in Celotex, foam, and cork are primarily responsible for the moderating characteristics of the material, while nitrogen is considered a weak neutron absorber. Table 7.1 shows the CHN content of the three materials (Heinrichs 2000). 
Table 7.1 CHN content of replacement materials.

\begin{tabular}{|l|c|c|c|c|}
\hline Material & C wt\% & H wt\% & N wt\% & Density \\
\hline Celotex & $49-50$ & 6 & $0.1-1$ & $15-18 \mathrm{lbs} / \mathrm{ft}^{3}$ \\
\hline FR-3730 Foam & 61.9 & 6.4 & 6.4 & $30 \mathrm{lbs} / \mathrm{ft}^{3}$ \\
\hline F28 Cork & 61.9 & 7.7 & 1.4 & $14-16 \mathrm{lbs} / \mathrm{ft}^{3}$ \\
\hline
\end{tabular}

The data indicate that all three materials contain roughly the same amount of the materials of interest and hence one should expect them to behave similarly under normal conditions if the geometry is the same. Replacing Celotex with an equal volume of FR-3730 foam should reduce $\mathrm{k}_{\mathrm{eff}}$ substantially and allow storage of an unlimited number of packages. Replacement of Celotex with cork of the same density should not significantly alter the criticality safety performance of the packaging. The use of cork may result in a slightly reduced $\mathrm{k}_{\mathrm{eff}}$ due to increased hydrogen and nitrogen content.

In his analysis of Celotex alternatives, Heinrichs notes that Pantex had addressed a major criticality concern that had been raised in earlier analyses - the loss of insulating/moderating material in a fire citing a Pantex memo concluding that the loss of Celotex in a container in a postulated fire event is beyond unlikely (Heinrichs 2000). Noting that improved fire safety performance enhances criticality safety, he endorses replacing Celotex with a superior fire performer. See Section 7.3.

In summary, foam and cork look very promising from a criticality safety standpoint; however, cork may require the use of additional poisons to allow unlimited arrays.

\subsection{Fire Protection}

In addition to acting as an impact absorber for the container, the insulation material must also protect the payload from fires as stated in $10 \mathrm{CFR} 71$ (30 minutes at $\left.1,475^{\circ} \mathrm{F}\right)$. Under $\mathrm{HAC}$, the insulation must protect the package to prevent the dispersal of any nuclear material. At the same time, it is important that the content of each package remains in the predetermined geometry to keep the criticality index low. Celotex, cork, and the FR-3700 foam are all organic materials and, like most organic materials, they all have a similar mechanism for protecting the inner container of the AL-R8 SI package from fire. The mechanism works by charring the outer layer exposed to the high heat flux from the fire since oxygen is excluded from the reaction by the closed steel drum. The charred layer then protects the package by two mechanisms. First, the charred layer acts as a barrier that slows the heat transfer through the walls of the container layers. Second, as the temperature of the charred layer increases, the material ablates and removes heat from the remaining material. The single vent hole in the drum lid vents the hot gases and prevents the chimney effect, thereby keeping post-fire smoldering to a minimum.

For Celotex, the packaging basics were described initially by Lewallen in 1972, and later explained in more detail in 1988 by Towell. The Lewallen (1972) report demonstrates that the char depth of Celotex is a function of thickness. For a container with similar Celotex thickness as the AL-R8 SI, the char depth was found to be about 2 in.

For the SAFKEG 2863B, a package that relied on cork as its primary insulating material, the mechanics appear to be quite similar. During the thermal testing of the 2863B, for example, the only obvious damage to the cork insulation was to the charred layer on the top of the package that reached a depth of 1.26 in. The underlying layer(s) of cork were undamaged to a depth of 1.57 in. Except for some obvious 
discoloration, the cork insulation on the sides and bottom of the package did not show any other damage (LANL 1997c).

In the case of FR-3700 polyurethane foam, which is a thermoset plastic, the dominant fire protection mechanism is the production of intumescent char. Under high temperatures, the foam produces intumescent char that breaks down very slowly at 2,000 to $2,200^{\circ} \mathrm{F}$. This intumescent char also expands into any large voids or cracks and seals the inner container from direct exposure to the fire.

The foam has performed well in tests performed according to the requirements of 10 CFR 71 . The foam, however, will generate considerably more gases at the higher temperature and lose more weight at the end of the 30-minute fire test as compared to Celotex. The percent of foam remaining is dependent on the weight density of the foam, with the higher density foam losing a smaller percentage of its original weight after a 30-minute fire as shown in Table 7.2. The weight loss will continue if the fire continues after 30 minutes (see Figure 7.1) (General Plastics 1991a; General Plastics 1991b). As the process of intumescence continues, it will protect the inner package until most of the foam is consumed.

Table 7.2 Percent weight loss as a function of density after a 30 -minute fire at $1,475^{\circ} \mathrm{F}$.

\begin{tabular}{|c|c|}
\hline Foam & \% Weight Loss \\
\hline FR-3715 & $34 \%$ \\
\hline FR-3730 & $17 \%$ \\
\hline
\end{tabular}

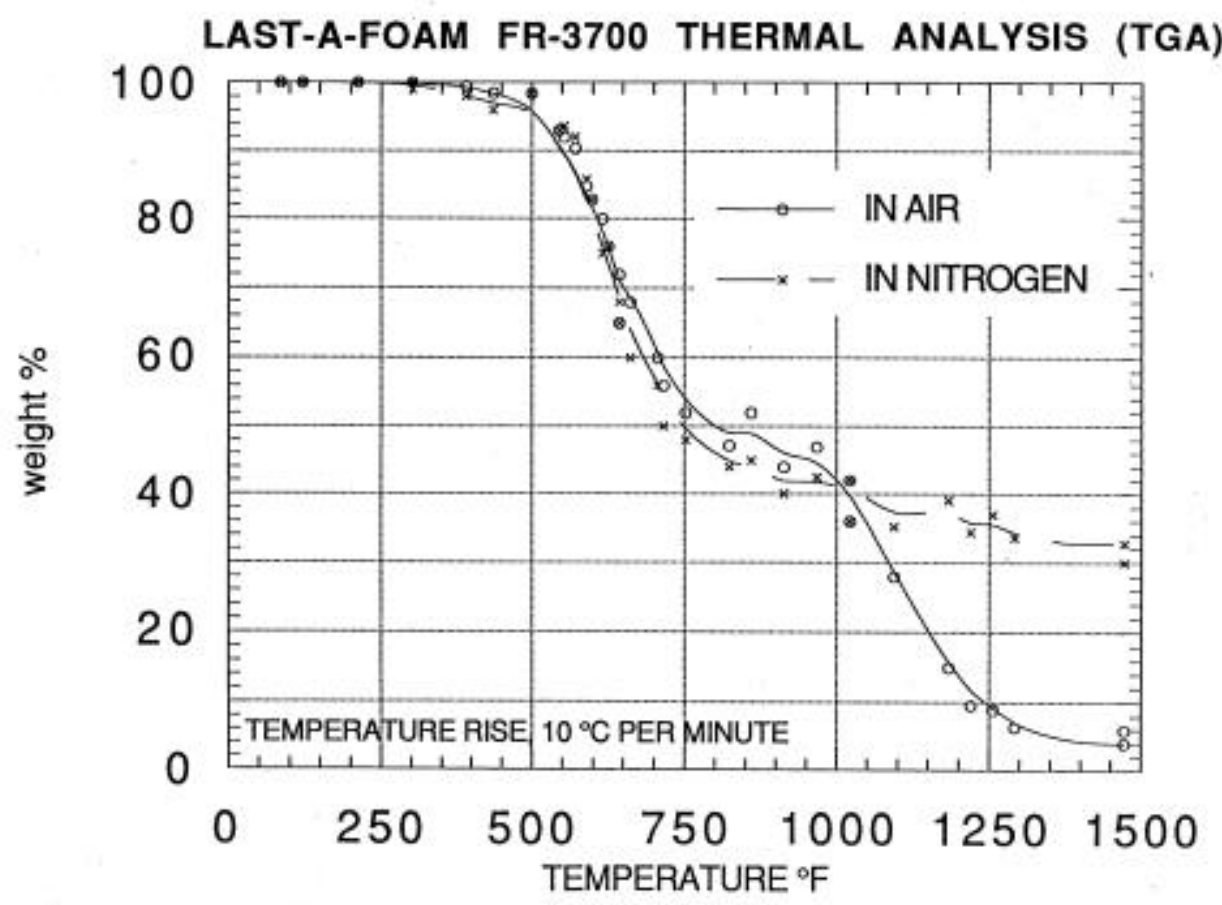

Figure 7.1 Effect of fire on FR-3700 foam. 
Table 7.3 compares the performance of the foam and Celotex after 30 minutes in a fire test. Celotex data were taken from the AL-R8 SARP (Adcock 1990). Testing was conducted on a full package inside a furnace with the temperature set to the required $1,475^{\circ} \mathrm{F}$. The foam data are from a test done by General Plastics on a sample inside a 5-gal steel container using a torch to simulate the fire (General Plastics 1991a; General Plastics 1991b). See Figure 7.2 for the test setup.

\section{TEST ARRANGEMENT}

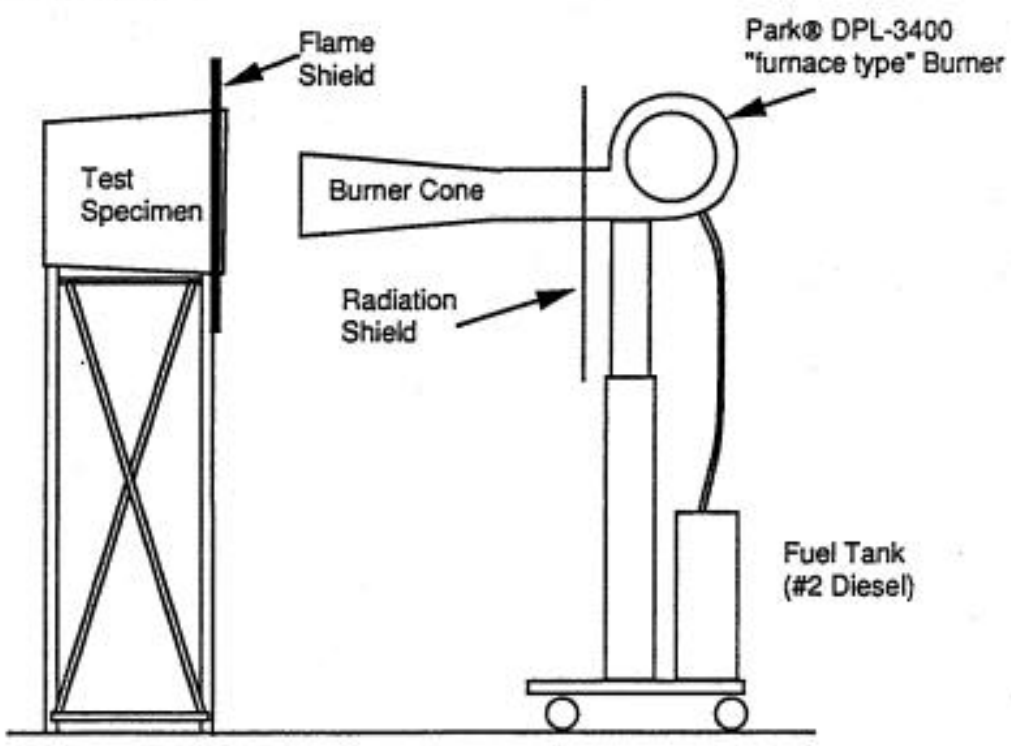

Figure 7.2 Test setup for the foam fire test conducted by General Plastic.

Table 7.3 Temperature gradient for sample test fire.

\begin{tabular}{|l|c|r|r|r|}
\hline \multicolumn{1}{|c|}{ Material } & Temp. at Surface $^{\circ} \mathbf{F}$ & 1 inch & 2 inches & 3 inches \\
\hline Celotex & 1,325 & 900 & 240 & 150 \\
\hline Foam FR-3730 & 2,049 & 838 & 323 & 86 \\
\hline Foam FR-3715 & 2,049 & 1,442 & 988 & 788 \\
\hline
\end{tabular}

Figure 7.3 shows the results of the char test performed at LLNL, where 1.5-inch-diameter by 1.5-inchhigh samples of Celotex, foam, and cork were heated to $500^{\circ} \mathrm{F}$. The char in the Celotex sample started to smoke at $300^{\circ} \mathrm{F}$. The char continued to smolder and expand even after removal from the furnace. The sample was then wrapped in aluminum foil to limit the air supply, but the char layer expanded from 0.12 inches to 0.5 inches before it stopped (see Figure 7.3). A new Celotex sample was added to the test and the sample was heated again in the furnace. Figure 7.3 shows that in less than 5 minutes, the Celotex turned into ashes, the foam lost $30 \%$ of its weight, and the cork sustained only slight discoloring. 


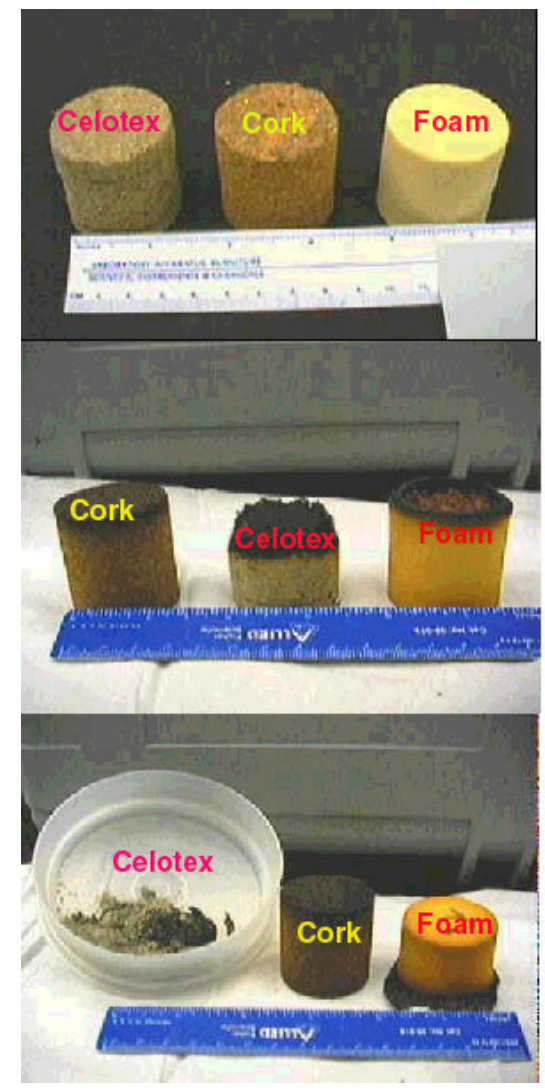

a) Sample before the test

b) Sample after 2 minutes at $300^{\circ} \mathrm{F}$

c) Sample after 5 minutes at $500^{\circ} \mathrm{F}$

Figure 7.3 Char test samples.

In actual service, because of the limited supply of air inside the steel drum, Celotex and foam would form a charred surface before the surface would be decomposed by heat.

The thermal analysis for the AL-R8 SI container with foam inserts indicates that the SI outer surface will reach a temperature of $460^{\circ} \mathrm{F}$ compared to $400^{\circ} \mathrm{F}$ for Celotex in a $1,472^{\circ} \mathrm{F}\left(800^{\circ} \mathrm{C}\right)$ fire. At $460^{\circ} \mathrm{F}$, the pressure inside the SI will reach 25 psi (Stein 2000). This pressure will generate a load of approximately $80 \mathrm{lbs}$ each for the bolts holding the SI lid, which is well within the safe loading for SI lid bolts (either carbon steel or Alloy 718). Analysis shows there will be no pressure rupture of the container and therefore the foam replacement material meets the fire safety requirement. 
This page is intentionally blank. 


\section{Summary/Comparison}

The performance of the FR-3700 foam material versus Celotex is summarized below and in Table 8.1.

\subsection{Shock Mitigation}

The low-density foam GP FR-3715 resulted in $g$-loading on the SI that is slightly lower than that for Celotex in the side-impact drop. Both foam and Celotex loading is in the least favorable direction, i.e., parallel to the lamination for Celotex and parallel to the rise direction for the foam. The cork provided the lowest shock levels, but the design tested was not stiff enough to prevent the SI flange from striking the inside of the outer drum.

\subsection{Thermal Performance}

The thermal conductivity of the foam is between $0.0317 \mathrm{~W} / \mathrm{m} \cdot \mathrm{K}$ for the $15 \mathrm{lb}$ and $0.068 \mathrm{~W} / \mathrm{m} \cdot \mathrm{K}$ for the 30 $\mathrm{lb}$ foam vs. $0.053-0.063 \mathrm{~W} / \mathrm{m} \cdot \mathrm{K}$ for Celotex. However, the thermal performance of the foam and Celotex is closely matched due to the design geometry of the foam. The actual pit surface to ambient temperature differences were within $1.5^{\circ} \mathrm{F}$. The ability to select a variety of foam densities and geometries allows flexibility in how the design meets thermal requirements.

\subsection{Fire Protection}

Celotex will perform slightly better in a fire environment where the oxygen is excluded from the Celotex; however, in the case where oxygen is present, the foam will perform much better than Celotex and will not contribute to the fire. Celotex will also smolder for a longer period after the fire as compared to the foam. Cork performed extremely well in the fire test, only showing a slight discoloration.

\subsection{Shielding}

The performance of the foam for shielding is slightly less than Celotex, but within the acceptance criteria for the AL-R8 SI, as the foam thickness is reduced in the middle section of the container under NCT and HAC. Alternate foam designs could be pursued if increased shielding is desired.

\subsection{Criticality}

The performance of the foam for criticality is equal to or better than the Celotex performance under NCT and HAC and within the acceptance criteria for the AL-R8 SI. Celotex density, however, varies within a much larger band than the foam. This variation would have an impact on the criticality analysis since the analysis is based on specific density. Cork designs may require the use of additional poisons to allow unlimited arrays.

\subsection{Handling}

A molded foam insert will reduce the amount of handling and eliminate the source of dust generated while handling Celotex. The parts geometry for the $30-\mathrm{lb}$ foam and the $15-\mathrm{lb}$ foam is unique to function and location and, therefore, is not interchangeable. The foam can only be assembled in the correct position. 


\subsection{Compatibility}

The primary motivation for this study was to evaluate materials that could perform as well Celotex in the AL-R8 SI without corrosion issues. The GP FR-3700 family of foams is much superior to Celotex since it contains about a fifth the moisture and a factor of 250 less chlorine than Celotex, as shown in Table 8.1.

\subsection{Comparison of Celotex and Foam}

Table 8.1 provides a comparative summary of the Celotex and foam performance based on research, testing, and analysis performed during this study. Cork has not been included in the table. It was considered a less advantageous replacement material due to the potential need for additional poisons to avoid criticality concerns for unlimited arrays, potential variability in its performance due to expected variations in natural materials, potential availability concerns for long term use, increased container weight, and cost associated with its use. However, cork does have advantages over foam in the areas of improved fire protection and increased shielding. If desired, shielding can be increased in the foam containers by careful selection of foam density and thickness to increase shielding while maintaining other design parameters in acceptable ranges.

Table 8.1 Comparative performance of Celotex and the GP FR-3700 foam.

\begin{tabular}{|c|c|c|}
\hline Requirement & Celotex* & GP FR-3700 Foam \\
\hline Chemical Compatibility & $1,760 \mathrm{mg} / \mathrm{kg}$ & $6.7 \mathrm{mg} / \mathrm{kg}$ \\
Cl & 8.6 & 1.7 \\
Nitrate & 10 & 0.7 \\
Phosphate & 182 & 5.1 \\
Sulfate & $6.9 \mathrm{wt} \%$ & $1.4 \mathrm{wt} \%$ \\
Moisture Content & See Figure 6.12 & See Figure 6.12 \\
Shock Mitigation & 0.053 & $0.03-0.067$ \\
Thermal Conductivity & Pass $1,475^{\circ} \mathrm{F} \mathrm{Fire}$ & Pass $1,475^{\circ} \mathrm{F} \mathrm{Fire}$ \\
Fire Protection & Meets $10 \mathrm{CFR} 71.47$ & Meets $10 \mathrm{CFR} 71.47$ \\
Shielding & Pass & Pass \\
Criticality & Low & Moderate $(\$ 300)$ \\
Cost & $40 \mathrm{lbs}$ & $34 \mathrm{lbs}$ \\
Weight & $15-18 \mathrm{lbs} / \mathrm{ft}^{3}$ & 15 and $30 \mathrm{lbs} / \mathrm{ft}^{3}$ \\
Density & Pass & Pass \\
Vibration & $>20$ Years & $>20$ Years \\
Aging (under radiation) & &
\end{tabular}

* Data from Porter 1999; Hansen 2000; Troyer 1997 


\section{Conclusions and Recommendations}

Celotex is an acceptable material for inserts in many radioactive material shipping and storage containers. Celotex is a good shock mitigator/insulator, does a fair job in fire protection (when oxygen is excluded), shielding, and criticality, and is inexpensive and easily available. However, because of its affinity to moisture and the resulting corrosive constituent, it may not be suitable for long-term storage applications when moisture is present and it is used with materials that can suffer corrosion attack.

Polyurethane foam inserts, on the other hand, are a good alternative to Celotex and may be the superior choice for applications where there are material compatibility concerns and fire resistance, thermal and structural performance requirements can be met using the foam. The design shown in Figure 5.1.a is an example where a combination of GP FR-3700 serie s Last-A-Foam materials were used to design a package meeting such requirements. Test and analysis have shown that this design met or exceeded the performance requirements of the AL-R8 SI using Celotex. Based on the tests and analysis conducted to date, the FR-3700 family of foams should be a good candidate to replace Celotex in AL-R8 SI containers. The current estimated cost of the material ( $\$ 300 /$ container) could be further reduced by working with the vendor to set up the manufacturing and molding process. 
This page is intentionally blank. 


\section{References}

Adcock, F., ed. 1990. "Rocky Flats Container, Model AL-R8, Safety Analysis Report for Packaging (SARP), (U),” RFE-8801, EG\&G Rocky Flats, Inc., September.

Addington, J. 2000a. "Qualification Plan, AL-R8 Sealed Insert (U)”, Issue F, Report PQ706035-001, Pantex, October.

Addington, J. 2000b. “Test Plan, AL-R8 Sealed Insert (U)”, Issue F, Report TK706035-001, Pantex, October.

Edmondson, D. 1994. "Initial Report of Tests. Last-a-Foam ${ }^{\circledR}$ FR-3710 for Consumers Power Company Palisades Power Plant Covert, Michigan," General Plastics Manufacturing Company, Report Number G-TR9411, November 16.

Foster, P. et al. 1999. "AL-R8 SI (Sealed Insert) (U), Thermal Experiment, Summary of Phase I," DOE/AL/65030-9902, March.

General Plastics Manufacturing Company. 1991a. "General Plastics Last-a-Foam ${ }^{\circledast}$ FR-3700 for Crash \& Fire Protection of Nuclear Material Shipping Containers," General Plastics Manufacturing Company, Tacoma, Washington, Initial Issue, April 1991. See "Fire Resistance Performance" dated August 13, 1990 in the section titled Fire.

General Plastics Manufacturing Company. 1991b. "General Plastics Last-a-Foam ${ }^{\circledR}$ FR-3700 for Crash \& Fire Protection of Nuclear Material Shipping Containers," General Plastics Manufacturing Company, Tacoma, Washington, Initial Issue, April 1991. See "Thermal Decomposition of Last-a-Foam ${ }^{\circledR}$ FR-3700" by Floyd P. Henry, dated January 31, 1991 in the section titled Fire.

General Plastics Manufacturing Company. 2002. "Interactive Technical Data Sheets," General Plastics Manufacturing Company, Tacoma, Washington, http://www.generalplastics.com/cgibin/density/density.cgi, April.

Hansen, L. 2000. L. Hansen, letter correspondence to S. Abdallah, "Celotex Replacement in the AL-R8 SI Container (U)," Lawrence Livermore National Laboratory, CODT-2002-1371, January 21.

Heinrichs, D. 1999. "Review Comments on NCS-019, Rev.0 (AL-R8 SI/NCSE) (U),” Criticality Safety Group, CSAM-99-145, June 11.

Heinrichs, D. 2000. "Replacement of Celotex With Cork or Foam in the AL-R8 SI (U)," Criticality Safety Group, CSAM-00-224, October 19.

Lawrence Livermore National Laboratory. 1998. R. Bailey, letter correspondence to S. Hallet, Mason \& Hanger - Silas Mason Co., Inc. Pantex Plant, regarding Zone 4 Thermal Studies, July 16.

Lawrence Livermore National Laboratory. 1999. "DYNA3D: A Nonlinear, Explicit, Three-dimensional Finite Element Code for Solid and Structural Mechanics (U)," Jerry I. Lin, Methods Development Group, Mechanical Engineering Department, October.

Lewallen, E. 1972. "Drum and Board-Type Insulation Overpacks of Shipping Packages for Radioactive Materials (U)," E. I. Dupont de Nemours \& Co., Savannah River Laboratory, DP-1292, Aiken, SC, July. 
Los Alamos National Laboratory. 1997a. "Safety Analysis Report for Packaging SAFKEG 2863B (U)," LAUR-93-4509, Rev. 6, May 17. See, in particular, Table 2.4, "Properties of Insulating and Shock Absorbing Materials."

Los Alamos National Laboratory. 1997b. "MCNP - A General Monte Carlo N-Particle Transport Code (U)," Version 4B, Judith F. Briesmeister, ed., Los Alamos Report, LA-12625-M, March 1997.

Los Alamos National Laboratory. 1997c. "Safety Analysis Report for Packaging SAFKEG 2863B (U)," LAUR-93-4509, Rev. 6, May 17. See in particular, Chapter 3, Thermal Evaluation, and the associated test reports, TR 96/12/46, "HAC Thermal Test," TR 96/12/47, "HAC Thermal Test Temperature Measurements," TR/96/12/48, "Physical Effects of Thermal Test," and CTR 95/18, Issue A, "Summary of the Physical Properties and Composition of Resin Bonded Cork," all of which are dated March 27, 1997.

Porter, R. 1999. "Drop and Vibration Testing on One AL-R8 SI Pallet Assembly and Four Containers (U)," Report 42283-01, Wyle Laboratories, January.

Raboin, P. 2000. “AL R8 Drop Simulations,” unpublished experimental data, Lawrence Livermore National Laboratory.

Salamanca, A. 2002. Personal and e-mail communication from Adriano Salamanca who conducted the tests, recorded in lab notebook.

Stein, W. 1999. Interdepartmental Memorandum to S. Abdallah, "Thermal Response for Foam Insulated AL-R8 SI Containers (U)," Lawrence Livermore National Laboratory, TFG99-1211, December 29.

Stein, W. 2000. Interdepartmental memorandum to S. Abdallah. "Thermal and Pressure Response of a Replacement Foam AL-R8 SI to Hypothetical Fires (U)," Lawrence Livermore National Laboratory, Thermal Fluids Group, October 26.

Stein, W. et al. 2000. "Thermal Experiment Results for the Celotex Replacement AL-R8 Containers (U)," Lawrence Livermore National Laboratory, July 6.

Title 10, Code of Federal Regulations, Part 71 (10 CFR 71), "Compatibility with the International Atomic Energy Agency (IAEA)," 60 FR 50248, September 28, 1995, as amended.

Towell, R. 1988. "Important Features Affecting Thermal Protection Provided by Drum and Fiberboard Packages," Proceedings of the $29^{\text {th }}$ Annual Meeting of the Institute of Nuclear Materials Management, Vol. XVII, Las Vegas, NV.

Troyer, S. 1997. "Nuclear Criticality Safety Evaluation, AL-R8 SI Container Analysis (U)," Pantex Report NCS-019 Rev. 0, Mason and Hanger Corporation, August.

Woelffer, R. et al. 2001. "Drop Test of AL-R8 SI Container Four Packs (U)," CODTU-2000-2499, Lawrence Livermore National Laboratory, April. 


\section{Appendix A. Selected Engineering Drawings}




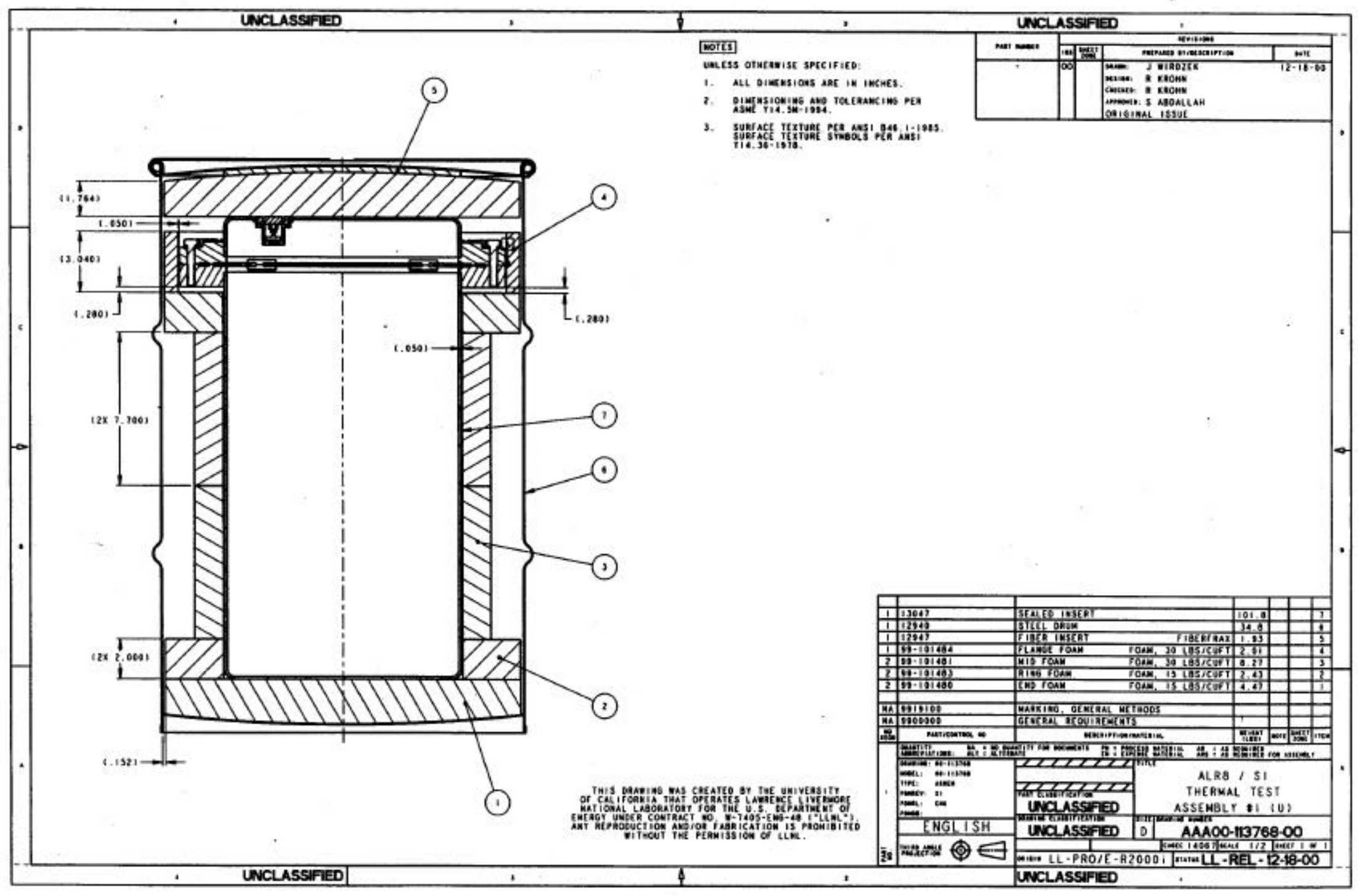

Figure A-1 Drawing Number AAA00-113768-00, AL-R8 SI Thermal Test Assembly 


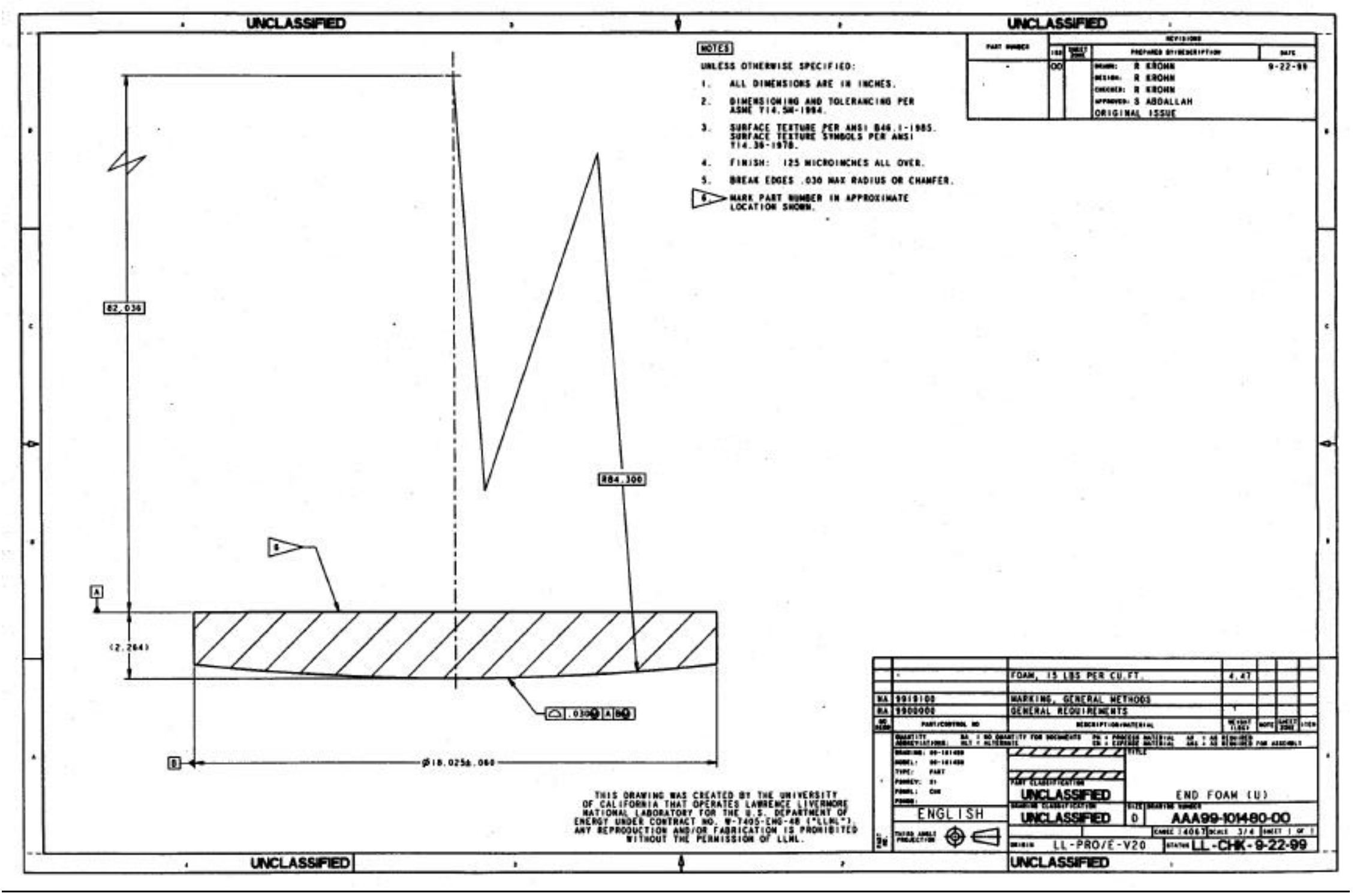

Figure A-2 Drawing Number AAA99-101480-00, End Foam 


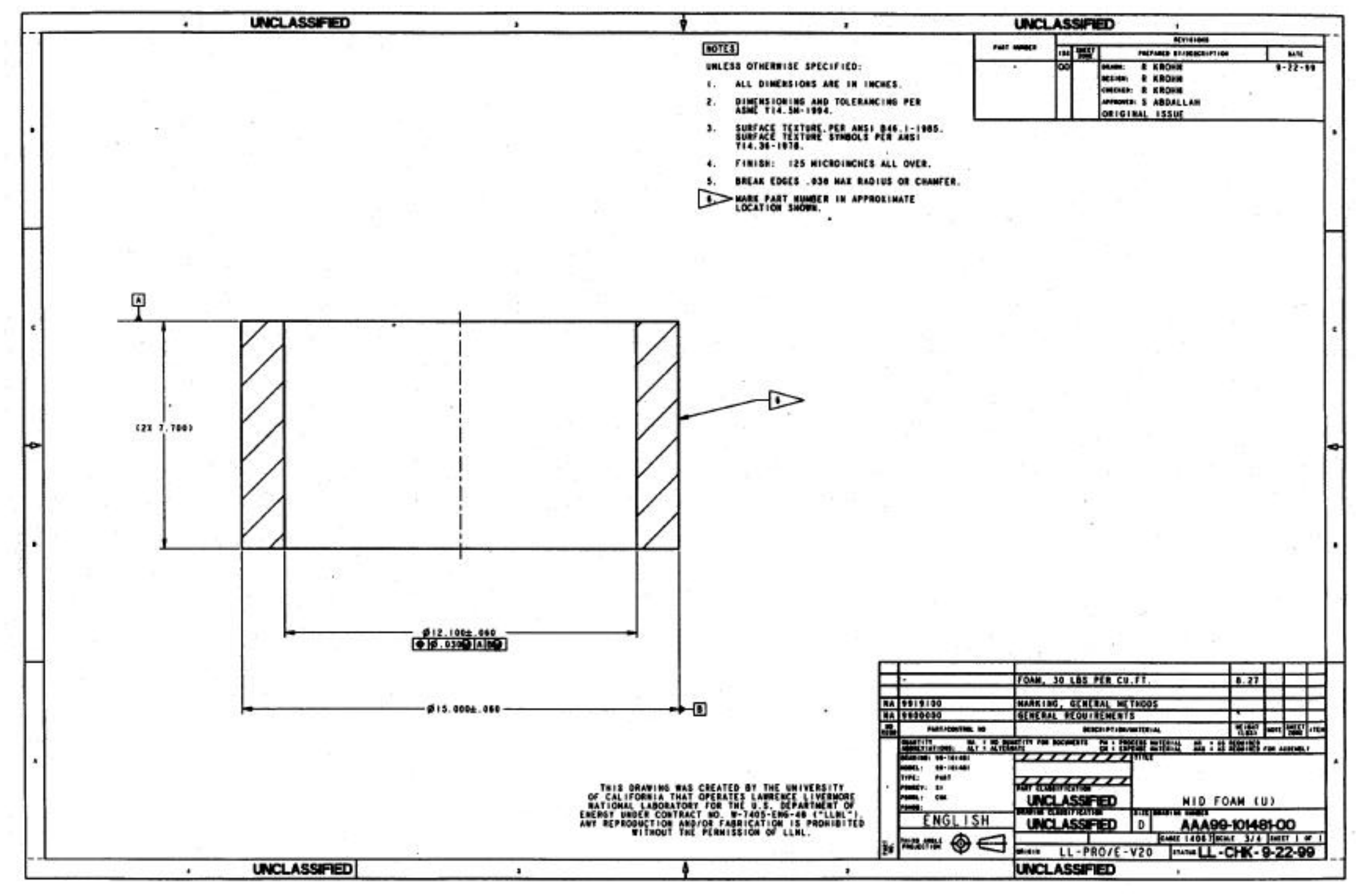

Figure A-3 Drawing Number AAA99-101481-00, Mid Foam 


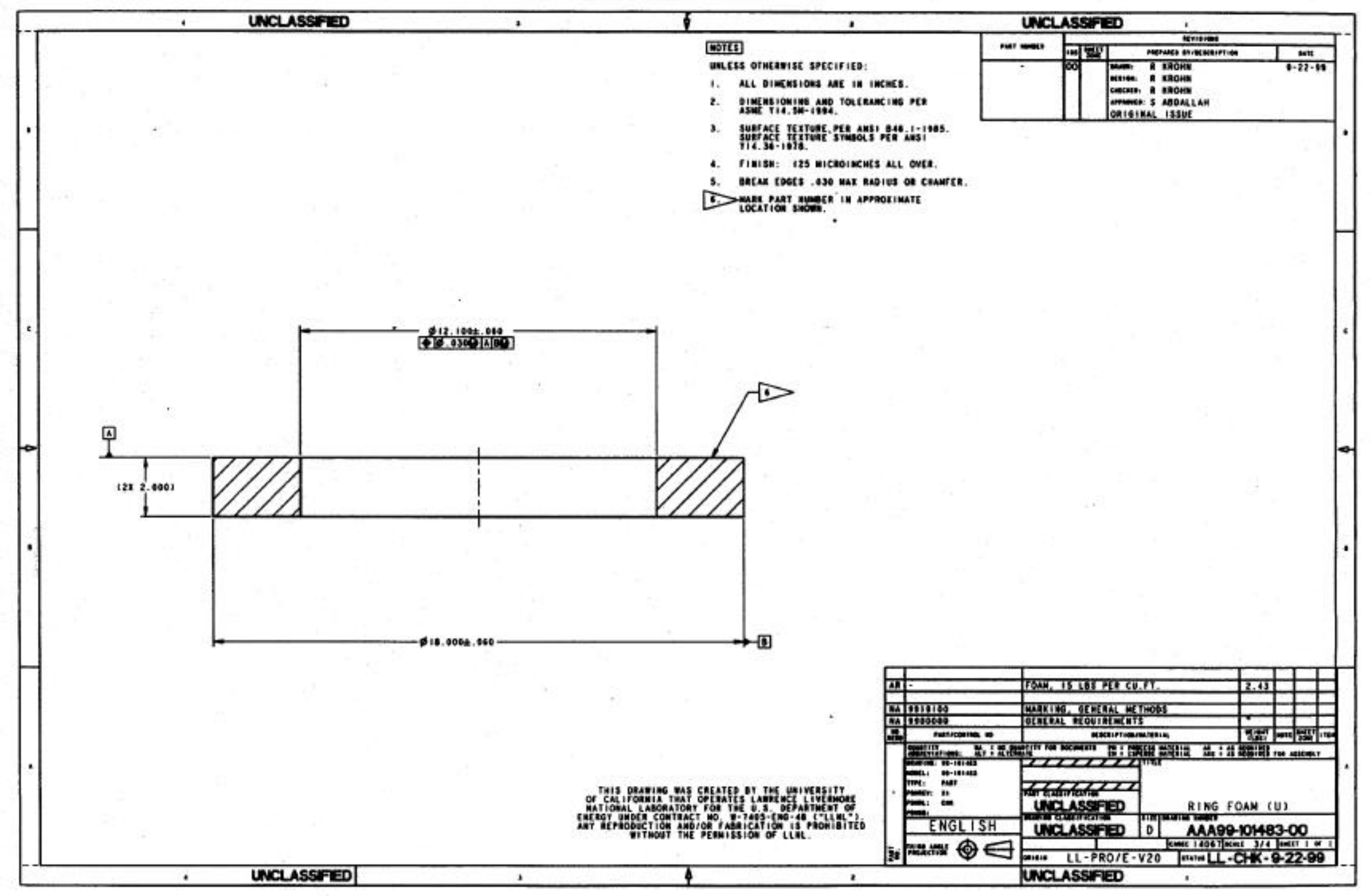

Figure A-4 Drawing Number AAA99-101483-00, Ring Foam 


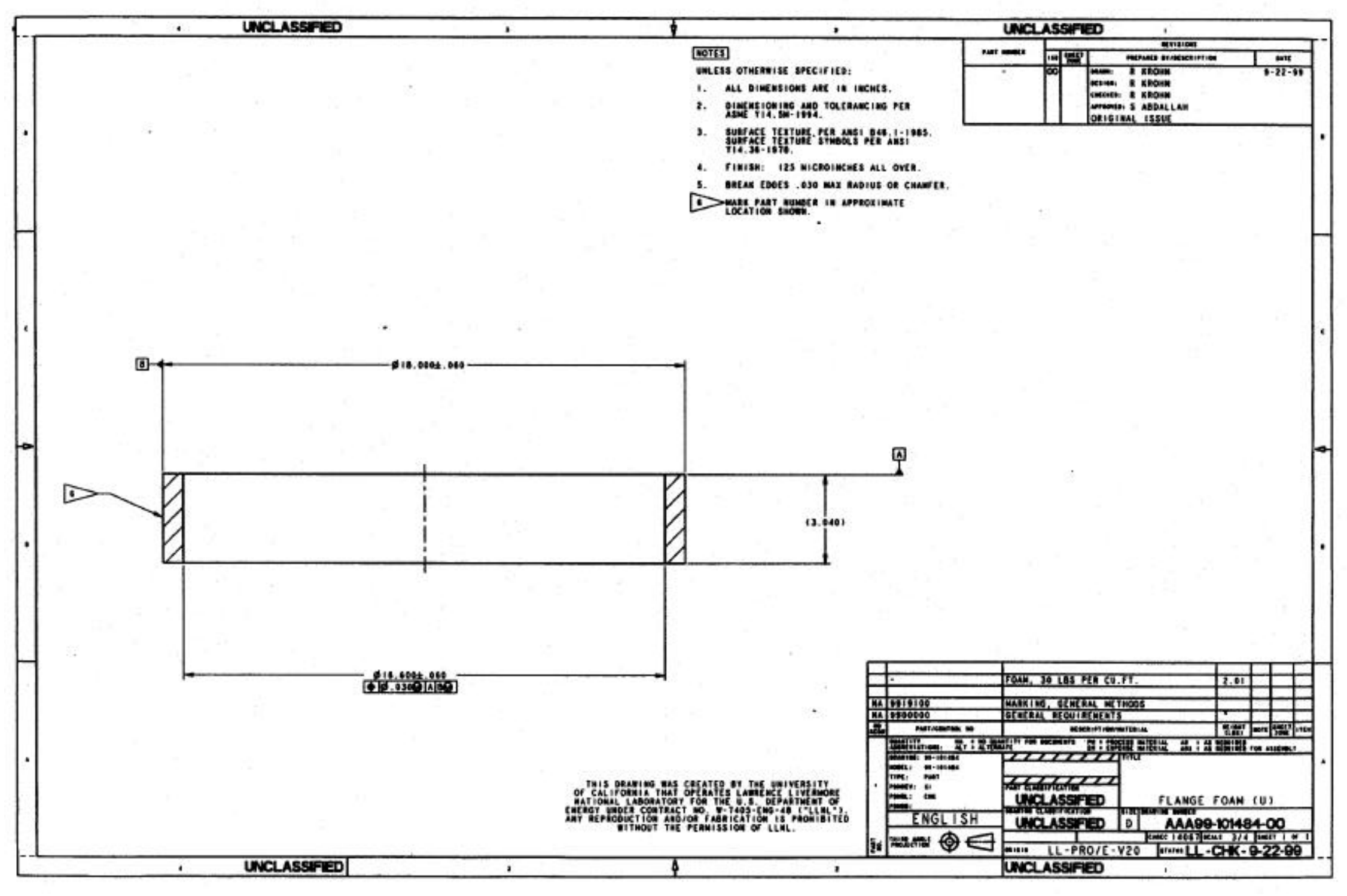

Figure A-5 Drawing Number AAA99-101484-00, Flange Foam 